\title{
Controls on monthly estuarine residuals: Eulerian circulation and elevation.
}

Jenny M. Brown ${ }^{a,{ }^{*}}$, Rodolfo Bolaños ${ }^{b}$, Alejandro J. Souza ${ }^{a}$

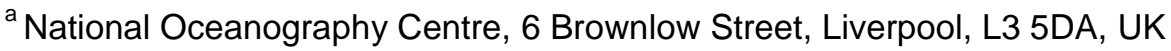

“jebro@noc.ac.uk

${ }^{\mathrm{b}}$ DHI, Agern Allé 5, DK-2970 Hørsholm, Denmark

Keywords: POLCOMS-WAM-GOTM model, Dee Estuary, hypertidal, baroclinicity, residual circulation, residual elevation, estuarine circulation, storm-surge

\section{Abstract}

The Dee Estuary, at the NW English - Welsh border, is a major asset, supporting: one of the largest wildlife habitats in Europe; industrial importance along the Welsh coastline; and residential and recreational usage along the English coast. Understanding of the residual elevation is important to determine the total water levels that inundate intertidal banks, especially during storms. While, improved knowledge of the 3D residual circulation is important in determining particle transport pathways to manage water quality and morphological change. Using mooring data obtained in February - March 2008, a 3D modelling system has been previously validated against in situ salinity, velocity, elevation and wave observations, to investigate the barotropic-baroclinic-wave interaction within this estuary under full realistic forcing. The system consists of a coupled circulation-wave-turbulence model (POLCOMS-WAMGOTM). Using this modelling system the contribution of different processes and their interactions to the monthly residuals in both elevation and circulation is now assessed. By studying a tidally-dominated estuary under wave influence, it is found that baroclinicity induced by a weak river flow has greater importance in generating a residual circulation than the waves, even at the estuary mouth. Although the monthly residual circulation is dominated by tidal and baroclinic processes; the residual estuarine surface elevation is primarily influenced by the seasonal external forcing to the region, with secondary influence from the local wind conditions. During storm conditions 3D radiation stress becomes important for both 
elevation and circulation at the event scale, but is found here to have little impact over monthly time

32 scales.

\section{Introduction}

In tidally influenced coastal water, shallow depths cause tidal residuals in addition to other process residuals, generated by the land-sea interface. Regions of Freshwater influence (ROFI's) have a complex 3D structure related to either permanent (e.g. Ise Bay, Japan, Kasai et al., 2000) or periodic stratification (e.g. Liverpool Bay, UK, Verspetch et al., 2009), as the result of tidal straining (Simpson et al., 1990). Storm surge local or external to a coastal system can generate significant residual elevations for a short period (Jones and Davies, 1998). However, seasonal patterns in meteorological conditions will influence the medium-term residual (a few months), although they are likely to be minimal over the longterm (at least a year). Since the dynamics of semi-enclosed systems are influenced by gradients in surface elevation, external hydrodynamic boundary forcing to a region can impact the circulation, especially during storm conditions (Li et al., 2010). Storm surges can cause a salt flux in and out of the estuary as the surge passes (Li et al., 2009), combined with wind straining (Scully at al., 2005) and enhanced wind mixing (Chen et al., 2009). During storm conditions these processes will influence the

47 typical stratified structure and in turn the gravitational circulation. In hypertidal areas the fast tidal currents influence the net transport of properties during flood and ebb. However, over the long-term the net transport will depend on asymmetries in the tidal flow and local processes creating a weak but continual, or frequent, circulation. Understanding this residual circulation is important for determining the long-term coastal pathways of dissolved or suspended particles at varying heights within the water column. Along the open coast the range determines the time-varying water depth and in combination with the storm

53 surge and wave set-up can be used to determine areas of inundation. However, in enclosed (estuarine)

54 systems the wave influence can be reduced through sheltering, and river influence can potentially modify water levels. Understanding inundation is important to investigate intertidal exchange processes/fluxes 56 and flood potential. the research into process dynamics of Bolaños et al. (2011; 2013; Submitted) and Brown et al., (2012a; 
term residuals is required for sustainable management planning. Two estuary channels (namely the Welsh and Hilbre Channels, Fig. 1) are studied to improve understanding of the physical processes (full external forcing to the outer Liverpool Bay boundary and local regional component forcing from: waves, 64 tide, local meteorology and baroclinicity) affecting the tide-dominant estuarine channels under episodic wave impact and baroclinic influence. Theoretical studies suggest the tidal residual will vary depending on the channel geometry (Li and O'Donnell, 2005), the Coriolis effect (Winant, 2008) and frictional

67 influence (Cáceres et al., 2003), as will the combined barotropic-baroclinic residual (Valle-Levinson et al., 2003). We therefore compare transects of two different channels to better understand the spatial variability within the net residual circulation. Based on Bolaños et al. (2013) the relevant non-dimensional numbers that are used to determine the characteristics of the Dee are the: horizontal Richardson number, Stokes number, Ekman number and Wedderburn number. The horizontal Richardson number (average value of 0.6 ) indicates a regime of tidal straining. It has also been shown that the gravitational circulation is important in creating residual circulation during calm periods (Bolaños et al., 2013). The Stokes number (Souza, 2013) is greater than 1 (average value of 5) suggesting tidal mixing (friction) to be important over the full water column. A low Ekman number (average value of 0.165 ) suggests Coriolis is important in creating horizontal shear. A large Wedderburn number (average value of -2.09) suggests wind to be important during this period. However, 3D numerical simulations by Bolaños et al., (2013) show very different characteristics within the estuary channels. The residual flow in the Welsh Channel is dominated by the tide, with a horizontally-sheared pattern (Bolaños et al., 2013). The residual in the Hilbre Channel is dominated by baroclinicity, creating a vertically-sheared pattern (Bolaños et al., 2013). Wave activity at the Welsh mooring is fairly consistent at all states of the tide due to its exposed location (Bolaños et al., submitted). The ebb tide causes wave steepening (higher and shorter period). Wave activity at the Hilbre mooring occurs at higher water elevations (above the mean tidal level). The influence of radiation stress, especially when considered in 3D, during the stormy period has been shown to improve the $3 \mathrm{D}$ structure of the along-channel residual velocity component at this mooring location (Bolaños et al., submitted). However, even under these more turbulent conditions the baroclinicity is still the most important process in creating a residual circulation for this channel (Bolaños et al., submitted). These earlier works are extended here to look at the longer term (monthly) spatial time-averaged residual in both elevation and circulation. Studies of the time-varying residual elevation (Brown et al., 2012a) and time-varying residual circulation (Brown et al., submitted) show the subtidal, event scale (few days) 
process contribution over time in response to the atmospheric, external hydrodynamic boundary and riverine forcing. The semi-diurnal variability in the magnitudes of these residuals is also shown to be a consequence of the interactions with the hypertide. Although storm processes, such as wind, waves, and river discharge have large instantaneous impact during extreme events (Brown et al., Submitted), over longer periods their influence may be minimal. To gain insight into the monthly residual conditions timeaveraged residuals are studied here by comparing equal spring-neap periods (15 days) of calm and stormy conditions. Further comparison with the full (30-day) period is used to determine the importance of

100

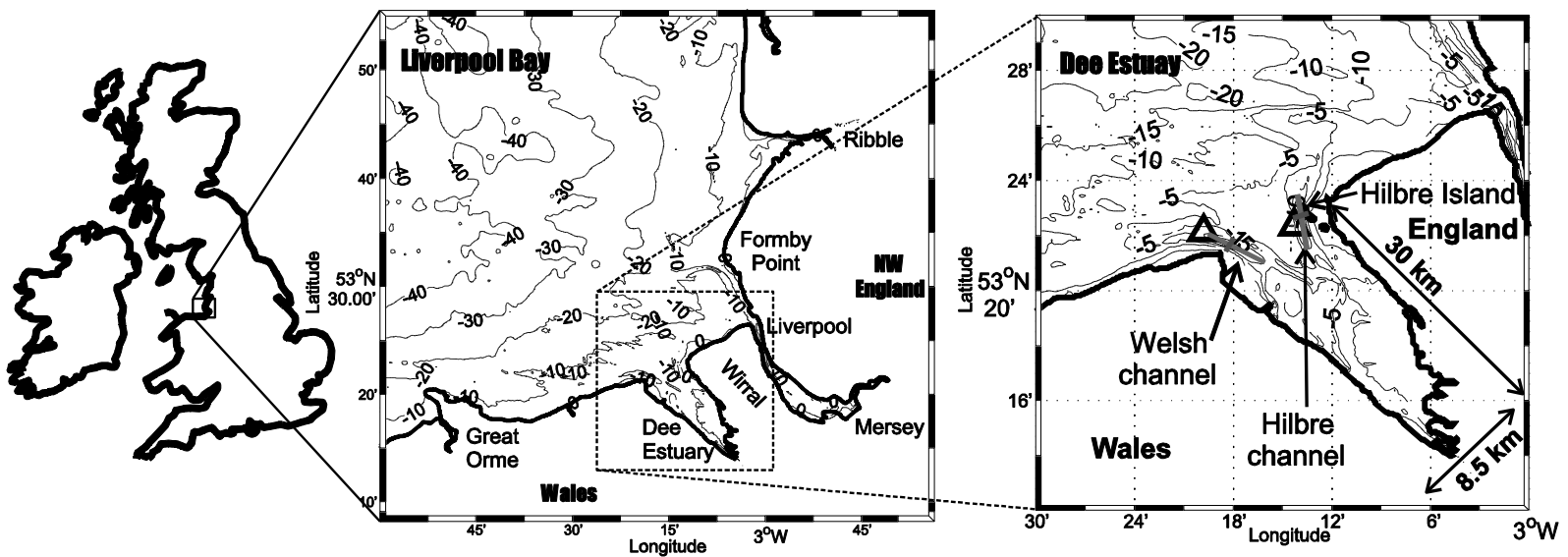

Figure 1. The Dee Estuary located in Liverpool Bay NW UK. The local model domain is shown (centre) with a close up of the estuary bathymetry (right) with instrument locations marked by the black triangle and the studied transects marked by grey lines.

The study period $\left(6^{\text {th }}\right.$ February $-7^{\text {th }}$ March 2008) covers 30 days in winter, which include calm currentdominant conditions (prior to $21^{\text {th }}$ February with $\mathrm{Hs}<0.7 \mathrm{~m}$ ) followed by stormy wave-current conditions, with an extreme storm occurring $29^{\text {th }}$ February, when the $H_{m 0}$ reaches up to $2.23 \mathrm{~m}$ within the channels close to the estuary mouth. During this time the following sources of observation are available from a process study of the Dee Estuary initiated on the $12^{\text {th }}$ February (Fig. 2 a-c): current data from an Acoustic Doppler Velocimeter (ADV, within the Welsh Channel) and Acoustic Doppler Current Profiler (ADCP, within the Hilbre Channel); wave parameters $\left(H_{m 0}\right.$ and $\left.T_{z}\right)$ from a pressure sensor; depth from the same pressure sensor. A 48 hour delay occurs between instrument deployments within the two channels. 
113 Details of the instrumentation used during this study are given by Bolaños and Souza (2010). Data is

114 also obtained from other sources to supplement this study (Fig. 2 d-e): Wind velocity $\left(U_{10}\right)$ from the met 115 station on Hilbre Island; and river discharge from gauging stations in tributaries feeding the Dee. During 116 this study (Fig. 2) the tidal range is about $4 \mathrm{~m}$ during neaps and $10 \mathrm{~m}$ during springs, generating 117 maximum currents of $1.4 \mathrm{~ms}^{-1}$. The waves within the estuary do not exceed $2.3 \mathrm{~m}$ during storms and are 118 below $0.7 \mathrm{~m}$ during calm or fetch limited (SE) wind conditions. The river discharge is generally low, often $119<80 \mathrm{~m}^{3} \mathrm{~s}^{-1}$ which is considered as large for the Dee. The wind is variable reaching a maximum of $23.5 \mathrm{~ms}^{-}$

$120{ }^{1}$ during an extreme SW storm event. The veering wind conditions during this storm event (Fig. 2d, $550-$ $121650 \mathrm{hrs}$ ) are known to create joint extreme surge and wave conditions in Liverpool Bay (Brown et al., 122 2010).

124 The modelled period of study is extended back in time from the start of the observations, so two separate 125 15-day (spring-neap) periods can be compared. The processes investigated are: baroclinicity, tides, 126 waves, river flow, atmospheric forcing and external hydrodynamic boundary forcing to the bay. The 127 residual is calculated from numerical methods and refers to the 15 or 30 day time-average of a process' 128 contribution and its inherent interactions with other processes, which may contribute further to the 129 deviation in the circulation or elevation from that of the harmonic tide. For example, baroclinicity 130 131 generates a flow due to the baroclinic pressure gradient, but also interacts with the tide to create asymmetric current profiles. In this study both of these processes have been considered within the 132 baroclinic current residual, although the latter interaction is due to both tidal and baroclinic influences 133 interacting together, the model only accounts for it when baroclinicity is considered.

135 By setting up a 3D circulation-wave model and validating it with the available data enables a greater 136 spatial area to be analysed. Previous studies have looked at and validated the time-varying residuals, of 137 both circulation (Brown et al., submitted) and elevation (Brown et al., 2012a) at an isolated point in both 138 channels. This study proceeds to now investigate the cross-sectional 15 or 30 day time-averaged residual 139 profile over cross-sections in both the along- and cross-channel directions. For this application the 140 Proudman Oceanographic Laboratory Coastal Ocean Modelling system (POLCOMS) is chosen with the 141 Wave Model (WAM) and the General Ocean Turbulence Model (GOTM), to provide a fully coupled 142 circulation-wave-turbulence model. POLCOMS (Holt and James, 2001) is a barotripic-baroclinic 3D 
circulation model. WAM (Komen et al., 1994) adapted for coastal water (Monbaliu et al., 2000) is a third generation spectral wave model that has been extended to include 3D radiation stress (using Mellor, 2005). GOTM (Umlauf, Burchard, 2005) enables a sophisticated turbulence scheme to be implemented, which is crucial in estuarine modelling. The ADCP within the Hilbre Channel enabled 3D validation of this modelling system (Brown et al. Submitted). The predictive capability of the model is high for the simulation of the total vertical current profile components (with a Willmott et al., (1985) agreement index of at least 0.98 , see Amoudry et al., this issue) and surface elevation (with an RMS error normalised by the maximum tidal range of 0.15 ). The time-averaged (Eulerian) residual circulation profile over the study period has better agreement in the along-current component and less accuracy in the cross-channel channel component, which shows over prediction of the two-layer structure (Bolaños et al., 2013). The coupled wave model performs with high accuracy, while the residual velocity is less accurate, particularly during the extreme storm event (Brown et al., Submitted). The depth- and time-varying total velocity for the fully coupled model simulation (PGW) has been validated here. In the major current component the model performs reliably with an $R^{2}$ value of 0.90 and $R M S$ error of $0.48 \mathrm{~ms}^{-1}$. In the minor current component the model is less accurate, with an $R^{2}$ value of 0.12 and $R M S$ error of $0.19 \mathrm{~ms}^{-1}$, due to over prediction of the 2-layered structure in the vertical. The time-averaged (Eulerian) residual for the period of observation ( $12^{\text {th }}$ February $-6^{\text {th }}$ March 2008) has a Willmott et al., (1985) agreement index of 0.78 for the along-channel current component and 0.07 in the cross-channel component. There is clearly a bias in the along-channel profile (Fig. 3a) and an over-prediction of the 2-layer vertical structure in the crosschannel component (Fig. 3b). The depth-mean of the absolute bias at each sigma level where observations are available is $0.03 \mathrm{~ms}^{-1}$ and $0.02 \mathrm{~ms}^{-1}$, for the respective current components. The representation of the main channel patterns gives confidence in the numerical system, such that it has been used here to study the 3D patterns within the Welsh Channel, where observations are sparse. Available near-bed observations ( $0.35 \mathrm{~m}$ above the bed) from the ADV in the Welsh Channel show the model is capable at accurately simulating the near-bed stress due to the current field (with an $R^{2}$ value of 0.75, Ramirez et al., this issue) and the surface elevation (with an RMS error normalised by the maximum tidal range of 0.15 ). Pressure sensors confirm that both the wave field (Bolaños et al., submitted) and residual elevation (Brown et al., 2012a) were well represented by the model in both channels. The model is therefore used here to extract the time-averaged (Eulerian) residual circulation both along and across 
172 both channels. Where the studied transects intersect the residual elevation is also investigated for this

173 monthly period.
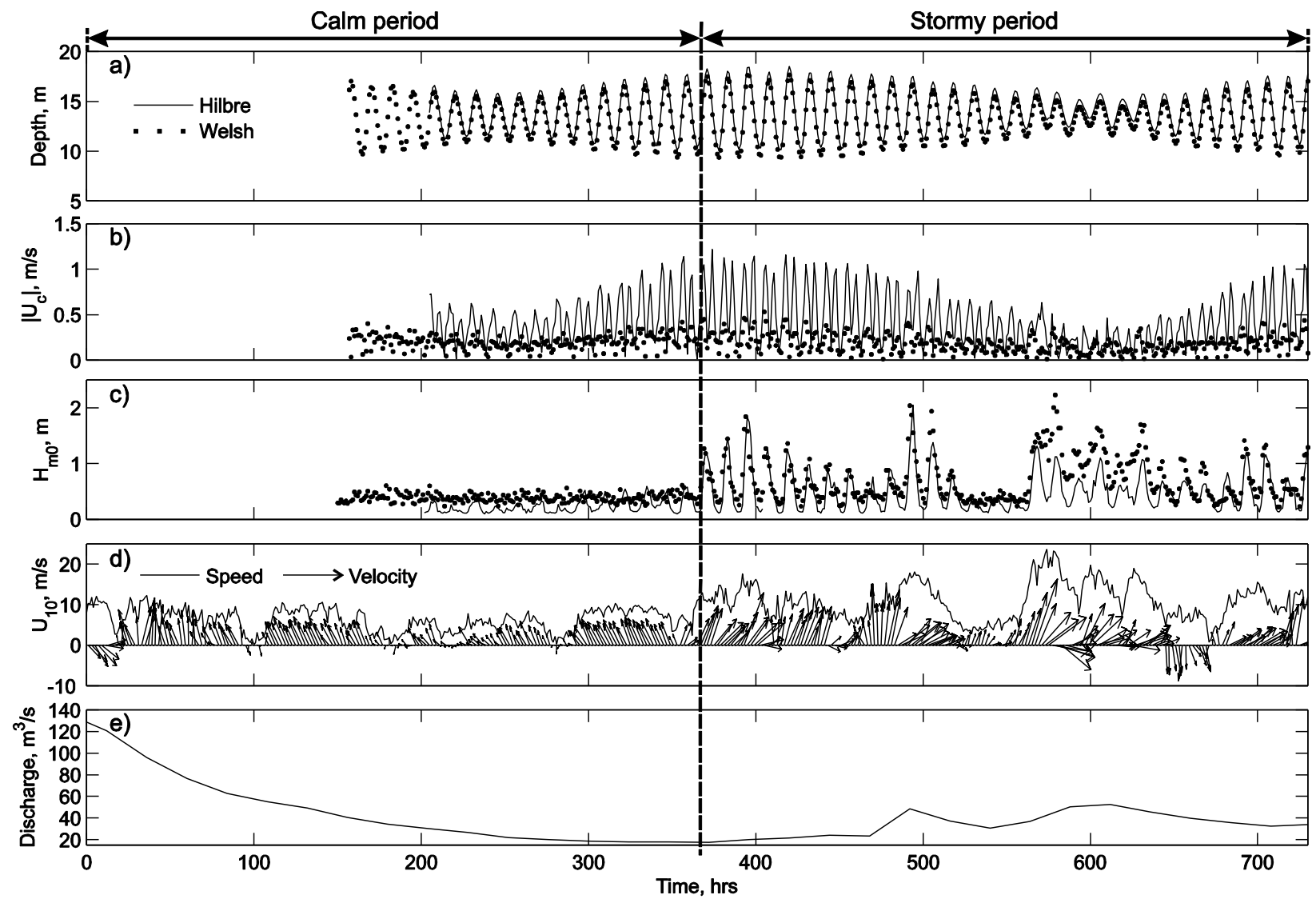

175 Figure 2. The observed channel depth (a), bottom current speed at $0.35 \mathrm{~m}$ above the bed in the Welsh

176 Channel and at $3.0 \mathrm{~m}$ above the bed in the Hilbre Channel (b), and significant wave height (c) for the

177 Welsh (dots) and Hilbre (solid line) channels. Along with the wind observed at Hilbre Island (d) and the combined river discharge gauged in the river Dee and Alyn (e). The time axis starts at 00:00 $6^{\text {th }}$ February

1792008 , with observations from the Dee Cruise (a-c) starting later on the $12^{\text {th }}$ February for the Welsh 180 Channel and $14^{\text {th }}$ February for the Hilbre Channel. The equal periods of calm and stormy (15-day) 

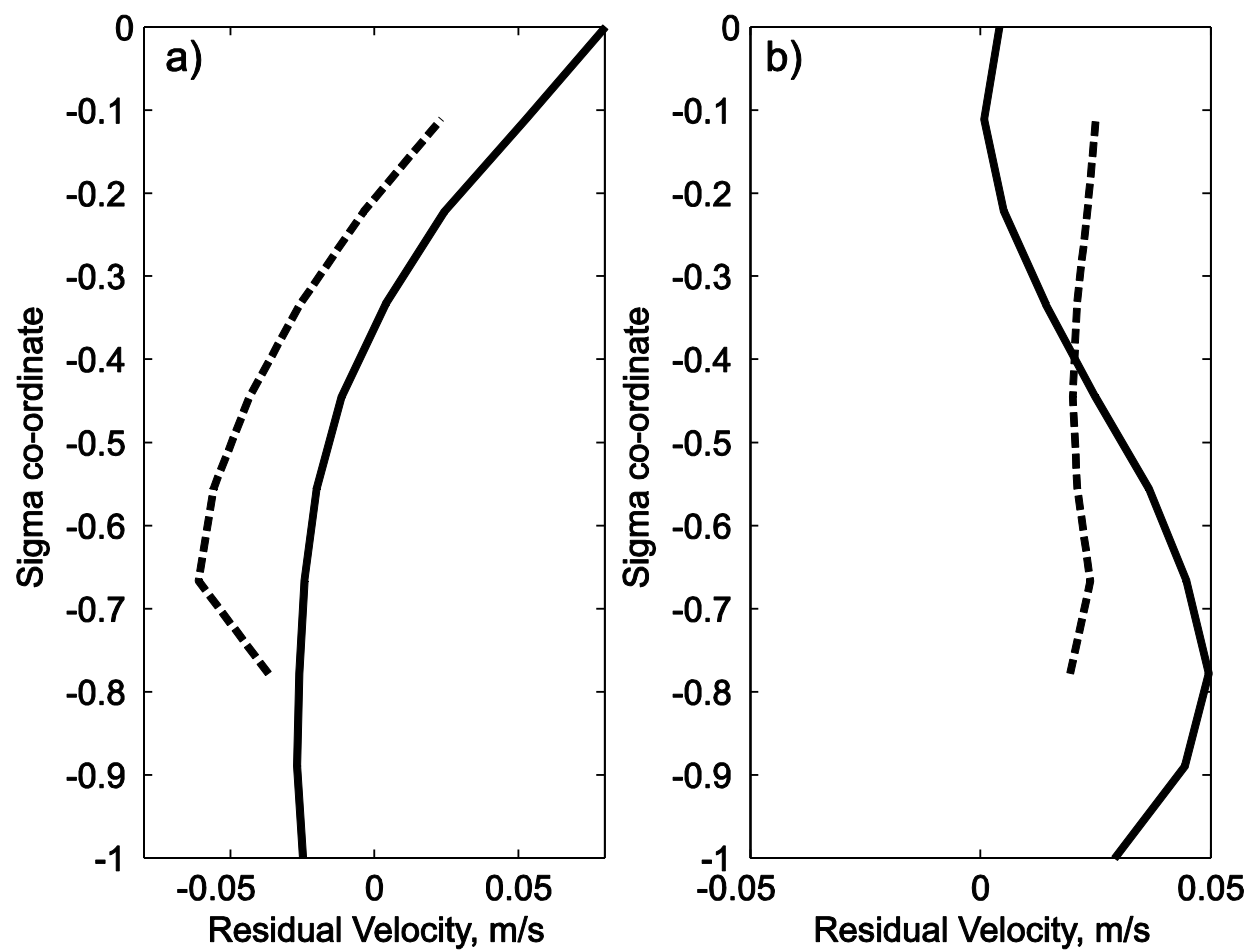

Figure 3. The modelled full physics (PGW, solid line) and measured (dashed line) time-averaged vertical current profile for both the (a) along and (b) across channel component for the full period of observation.

\section{Method}

This study investigates the barotropic-baroclinic-wave interaction within the Dee Estuary under full atmospheric, tidal and riverine forcing. The POLCOMS modelling system has been setup for Liverpool Bay at $180 \mathrm{~m}$ horizontal resolution with 10 vertical sigma co-ordinates, within the water column. The boundaries are forced by sequentially increasing resolution regional scale (Continental Shelf downscaled to Irish Sea) model output for surge and waves, to enable energy external to Liverpool Bay to propagate into the local regional domain (see Brown et al., 2010). Full meteorological forcing is provided operationally by the UK Met Office at $\sim 12 \mathrm{~km}$ resolution and 3 hourly intervals for temperature, humidity, cloud cover and at hourly intervals for wind and pressure. Available daily-averaged river discharge from the Centre of Ecology and Hydrology $(\mathrm{CEH})$ were used for freshwater sources. The model is spun up from $1^{\text {st }}$ January to create the 3D barotropic-baroclinic structure. The wave model is initiated on the $20^{\text {th }}$ February to allow a 1 day spin up of the wave conditions before the stormy period. This model setup ensures the model results are current-dominant during the calm period with no wave-circulation interaction. Realistic atmospheric and river forcing has been used for the full study period along with 
external boundary forcing to the Liverpool Bay model from a full physics Irish Sea simulation, which

202 includes: waves, tide, local meteorology and baroclinicity. In the earlier part of the study, prior to the 203 observational study in the Dee, the winds were south-easterly and greater river discharge occurred. 204 These fetch limited conditions would have caused minimal local surge (experienced mainly as a set 205 down, see later Figs. 4 and 5) and wave generation, while the river would have increased the baroclinic influence within the estuary. It is therefore justifiable to extend the calm current-dominated condition back 207 in time, since the conditions will be hypertidal with strong baroclinicity and local wind influence. The 208 second study period, of stormy conditions, refers not only to the consideration of waves, but also to increased external surge and local winds. The influence of every process is therefore analysed for each period. Methods to consistently extract the time-varying residual from observation and model simulation 211 have been described by Brown et al. (2012a) for validation purposes. The time-varying residual in both 212 elevation (Brown et al., 2012a) and circulation (Brown et al., submitted) has been validated to show good 213 hindcast of the residual elevation, but less accurate simulation of the residual circulation. These 214 validations are at point locations so slight inconsistency between the model and actual bathymetry, in 215 addition to loss of accuracy in the bathymetry due to horizontal model resolution, will cause noticeable error in local validation. However, the model has performed well when simulating seasonal circulation 217 across the Northwest European Shelf (Holt and Proctor, 2008), and both long-term circulation and density 218 fields more locally within Liverpool Bay (Polton et al., 2011). The model is therefore used here, to further 219 investigate the spatial monthly time-averaged (Eulerian) 3D circulation residual in the estuarine channels. 220 During this study period the time-averaged 3D circulation residual is qualitatively well hindcast for a point 221 in the Hilbre Channel (Bolaños et al., 2011; 2013). The validation of the east and north velocity 222 components (Bolaños et al., 2011) shows over prediction of the northerly surface velocity and a good 223 representation of the easterly velocity; while the validation of the along-channel and cross-channel 224 velocity components (Bolaños et al., 2013) shows better simulation of the along-channel component than 225 the cross-channel component. This demonstrates how influential the estuary bathymetry is on the 226 current. In each case the inclusion of wave coupling improves the modelled vertical residual circulation 227 profiles. The total study period ( $6^{\text {th }}$ February 00:00 to $7^{\text {th }}$ March 00:00) was chosen to enable two consecutive, calm followed by stormy, closed spring-neap cycles to be compared without the influence of 229 short-period tidal harmonic residuals influencing the time-averaged values. 
231 To investigate the monthly contribution from different processes to the residual elevation, the time-varying 232 elevation is extracted from the model for full and reduced physics simulations over 56 tides starting from

233 high water (Table 1). The difference between the simulated elevations provides the time-varying process 234 contribution, which is time-averaged over the three time intervals of interest (28 calm tides, 28 stormy 235 tides and the full period of 56 tides). For the full residual elevation the difference between the full physics 236 and tide only simulation is taken and the daily mean ( $25 \mathrm{hr})$ tidal elevation is interpolated to the hourly 237 model output intervals and added back to the residual elevation to incorporate the tidal influence. For the 238 tide-alone simulation the elevation is time-averaged over the spring-neap tidal periods to show how the 239 tidal elevation residual varies over time (for 2 closed cycles of 28 tides each, Figs. 4 and 5). The tidal 240 elevation is also time-average for the full period of interest.

242 The modelled currents are extracted at the sigma levels, which are at intervals of $10 \%$ of the water depth 243 at each model time step, to enable the same point in the vertical profile to be time-averaged providing the 244 Eulerian residual circulation. In an environment with such a large tidal range this removes issues of the 245 surface elevation varying drastically compared with the depth. The current velocities are presented at the 246 tide-mean depth of each sigma level, enabling the time-averaged (Eulerian) current profiles to be plotted 247 above the bottom topography relative to the mean tidal elevation. However, it should be noted that using 248 sigma levels complicates what the mean flow actually represents (Cheng et al., 2013) and is non249 conservative when time-averaging to obtain the volume flux, but the error due to this approach over time 250 is small (Deleersnijder and Beckers, 1992). Although the cross-channel surface slope varies within a tidal 251 cycle, the time-averaged slope is minimal and only deviates from the mean tidal level by at most a few 252 centimetres. The current profiles are therefore displayed for depths below the mean tidal elevation only 253 and the cross-sectional variation in residual elevation is not studied. The current components are 254 extracted at each model grid point over the channel transects. The $(u, v)$ components are then rotated 255 using principal component analysis to obtain the along- and cross-channel current components. The 256 spatial variability in the two current components is then studied for all the channel transects. The same 257 angle of rotation, defined by the full model simulation, is applied to every reduced process model 258 simulation considered. 

residual due to the complete external conditions, local waves, local meteorology and local baroclinicity are investigated. The residual is obtained by time-averaging chosen Liverpool Bay simulations and then taking the difference between model simulations with full forcing and reduced forcing, as stated in Table

1. This method allows important interactions, for example tidal interaction due to variable depth and current in a hypertidal estuary, to be included within the calculation of the process residual. Simply modelling the process in isolation would lose any interaction, which may be as important as the process itself (see Brown et al., submitted). Time-averaging determines the net residual in addition to the regular oscillation of the tide. Subtracting model simulations isolates the residual due to the required process of interest, which is not considered in the reduced forcing simulation. The model is used to simulate the

270 tides in isolation, include or omit temperature and salinity (i.e., choose between baroclinic or barotropic 271 simulation) and account or exclude boundary forcing, which includes: atmospheric, river source and 272 combined external (offshore) current, elevation, temperature and salinity fields. The residual created by 273 river flow is not studied since it is already known that the river has a weak flow close to the mouth during 274 this study, even at times of high discharge (Brown et al., submitted). By time-averaging the tide-alone current simulation and using the spring- and neap-mean tidal elevation the residuals induced by the tide

276 are also analysed. Due to the difficulty of selecting an averaging-window (tidal, daily) and the starting 277 point within a tidal cycle (due to the absolute amplitude of consecutive high and low water being different) 278 the longer period of a spring-neap phase (28 tides) has been used to time-average the residual tidal 279 elevation. To enable quantification of the process contribution to the total residual the time-averaged 280 (mean) value of each process generated residual elevation is compared with the total residual elevation, for the two 15-day and full 30-day periods. This enables the contribution of the calm and stormy period to 282 the full period to be assessed.

The model is used to extract the time-averaged current residual over transects of the channel and the residual surface elevation at a point where the transects intersect. The studied transect locations and dimensions are consistent with those investigated by Bolaños et al., (2013). The cross-sections are positioned over the elliptic scoured regions in the channels, extending along the channel between $15 \mathrm{~m}$ depth contours and across the channel between $5 \mathrm{~m}$ depth contours, cutting each other at right angles.

289 This gives transects of approximately $1000 \mathrm{~m}$ and $4000 \mathrm{~m}$ over a region of up to approximately $25 \mathrm{~m}$ 
depth. The point of intersection between the transects does not coincide with the deepest point of the

291 channel. By taking a straight along-channel transect allows the variation along the channel in the residual

292 circulation between opposite sides of the channel to be seen due to slight outward channel curvature

293 towards the mouth (Fig. 1). The modelled 3D current is time-averaged over the two 15-day periods in

294 isolation and the full 30-day period. To enable quantification of separate process contribution to the overall (full physics) residual circulation the RMS difference of time-averaged cross-sectional values has been calculated between the complete physics simulation and the different reduced physics simulations. This RMS value quantifies the difference between the total residual circulation (complete physics simulation) and the isolated process component of the residual circulation (reduced physics simulation), giving an estimate of the process contribution. The closer the RMS difference is to zero the more the analysed process contributes to the overall residual circulation. A value of zero means the total residual circulation is due to that one process alone. This difference metric calculates the contribution over a chosen time period and is extended here to consider spatial variation, by taking the cross-sectional-mean. The time-varying process contribution has been studies in more detail by Brown et al. (submitted). This is extended here to calculate the contribution of processes during 15-day (spring-neap) periods of calm and stormy conditions. Comparison with the contribution during the total 30 -day period enables the importance of different processes over monthly time scales to be deduced in relation to storm activity to obtain an understanding of the spatial pattern.

Table 1: The local Liverpool Bay model runs used to obtain the time-varying residual components, to which time-averaging is applied to obtain the net residual during the study period. The '-' symbol indicated the difference between model runs.

\begin{tabular}{|l|l|}
\hline $\begin{array}{c}\text { Processes } \\
\text { studied }\end{array}$ & \multicolumn{1}{c|}{ Model simulations used } \\
\hline All & POLCOMS-GOTM with full forcing coupled to WAM for the $2^{\text {nd }}$ 15-day period \\
\hline Met & POLCOMS-GOTM with full forcing - POLCOMS-GOTM without atmospheric forcing \\
\hline Baroc & POLCOMS-GOTM with full forcing - POLCOMS-GOTM without baroclinic forcing \\
\hline Wave & POLCOMS-GOTM-WAM with full forcing-POLCOMS-GOTM with full forcing \\
\hline Ext & POLCOMS-GOTM with full forcing - Met - Baroc - Tide \\
\hline Tide & POLCOMS-GOTM with only tidal forcing \\
\hline
\end{tabular}

\section{Results}


315 The residual elevation and residual circulation within the Welsh and Hilbre Channel is modelled to gain 316 insight into the processes contributing to 30-day residual conditions. The time-varying residual elevation

317 is initially analysed for the full (30-day) study period. It is extracted at the point of intersection between the 318 two studied transects, which are used to investigate the current residual. This point is located by a cross 319 in the along- and cross-channel transects (Figs. 6-17). The residual circulation is then presented for the calm 15-day period, followed by the stormy 15-day period and the combined monthly (30-day) period. The

321 residual circulation is split into the along- and cross-channel current components and shown for both the 322 along- and cross-channel transects.

\section{Residual elevation}

325 The time-varying elevation residual is very similar between both the Welsh (Fig. 4) and Hilbre (Fig. 5) 326 Channels. The value of the time-mean clearly shows the similarity between the channels and the 327 contribution of isolated processes to the overall residual elevation (Table 2). When decomposed into 328 isolated processes the external residual is clearly shown to be the most important factor contributing to 329 the instantaneous change in elevation and the local meteorology is secondary. Prior to the stormy conditions the external residual causes a set-down. During the stormy period an overall set-up occurs although the variation in the magnitude over time is highly changeable. The maximum deviation in the external residual elevation is much larger during the stormy period than the calm period. The local meteorological residual has a similar underlying pattern to that of the external residual, due to them both having the same forcing but over different size basins. The greater fetch across the Irish Sea creates a larger surge than that generated locally within Liverpool Bay. The waves, when present, tides and baroclinicity have a small contribution, ranked from largest to smallest in the order they are mentioned.

337 Baroclinicity causes a greater residual at neap tide than spring tide, with an overall positive bias. At times 338 the waves can have a comparable contribution to the local meteorology, while at other instances their influence will be less. This depends on wind direction and duration. The fetches for local wave and local 340 surge generation and propagation towards the estuary mouth can differ. The wave-induced residual 341 elevation can vary substantially across the estuary channels. A previous study (Brown et al., 2012a) at 342 the Hilbre and Welsh Channel mooring locations (Fig. 1) showed the wave contribution to be less than $343 \sim 0.05 \mathrm{~m}$. Here, the wave contribution is much greater (up to $1.13 \mathrm{~m}$ in the Welsh Channel and $1.18 \mathrm{~m}$ in 344 the Hilbre Channel). For this study the analysis locations are further within the Welsh Channel away from 
the ebb shoal in a deeper more exposed section of the channel; and further out of the Hilbre Channel towards the open sea and wave influence. The other process residual elevations are similar to those observed at the nearby mooring locations. All the component elevation residuals have semi-diurnal oscillation within them due to the strong process interaction with the hypertidal conditions (Figs. 4 and 5). Over the spring-neap periods the residual elevation is near zero (Table 2, Fig. 4 and 5, top panel). For shorter periods within the cycle (e.g. a single tide, neap or spring phase) the residual elevations can vary due to the imbalance of the tidal amplitude between adjacent high and low waters. During spring tides the high water amplitude is often larger than both the prior and subsequent low water amplitudes, the maximum tidal amplitude therefore occurring at high water. During neap tides the high water amplitude is generally between the prior and subsequent low water amplitudes with the smallest tidal amplitude occurring at low water. In both channels the neap tide set-down is just larger than the spring tide set-up, creating a 28 -tide residual elevation of $-0.001 \mathrm{~m}$ to $-0.005 \mathrm{~m}$. Earlier studies at the mooring locations (Brown et al., submitted) have investigated the time-varying residual tidal flow, which may also cause the non-zero residual tidal elevations. During spring tides there is a strong tidal residual flow out of the estuary in the Welsh Channel and moderate tidal residual flow into the estuary within the Hilbre Channel. During neaps a weak tidal residual flow into the Welsh Channel and moderate tidal residual flow out of the Hilbre Channel occurs. This demonstrated the spatial complexity of the tidal residual circulation within the estuary.

The time-mean residual elevation for each process is given for: the full study period, the calm period and the stormy period (Table 2). Since the wave model was only used for the stormy period only values in the associated table column are given. The overall residual elevation is mostly dependent on the external residual and then the local wind forcing during stormy periods (see by the low RMS values Table 2). All processes have similar influence on both channels. Comparison of the calm period with the stormy period shows that the external and local meteorological forcing both have greater mean values during 370 calm conditions. This is due to a continuous set-down compared with a varying set-up and set-down 371 during the stormy period which cancels out over the averaging window. Although the external and 372 meteorological residuals can vary in direction, the mean baroclinic effect is always positive. During the 373 stormy period there is less semi diurnal oscillation within the baroclinic residual elevation; suggesting, 374 tide-baroclinic interaction is weaker due to increased mixing reducing the strength of the stratification. At 
375 this time the (smoother) residual tends towards the higher value, causing a larger residual elevation on 376 average. The tides are averaged over 28 cycles starting at high water each side of the onset of wavy 377 conditions (the high water at $360 \mathrm{hrs}$ in Fig. 2). Differences in the tidal residual elevation values between 378 the calm and stormy period are $4 \mathrm{~mm}$ in the Welsh and $6 \mathrm{~mm}$ in the Hilbre Channels. This is most likely 379 due to the hourly frequency of model output limiting the accuracy of the representation of the tidal 380 elevation. However, slight differences will also occur due to the longer period tidal constituents influencing 381 the tide during the averaging windows. The tidally driven residual elevation will be unaffected by calm 382 and stormy conditions, and will only represent a mean of the tidal elevation during the analysis period, 383 which is nearly negligible.
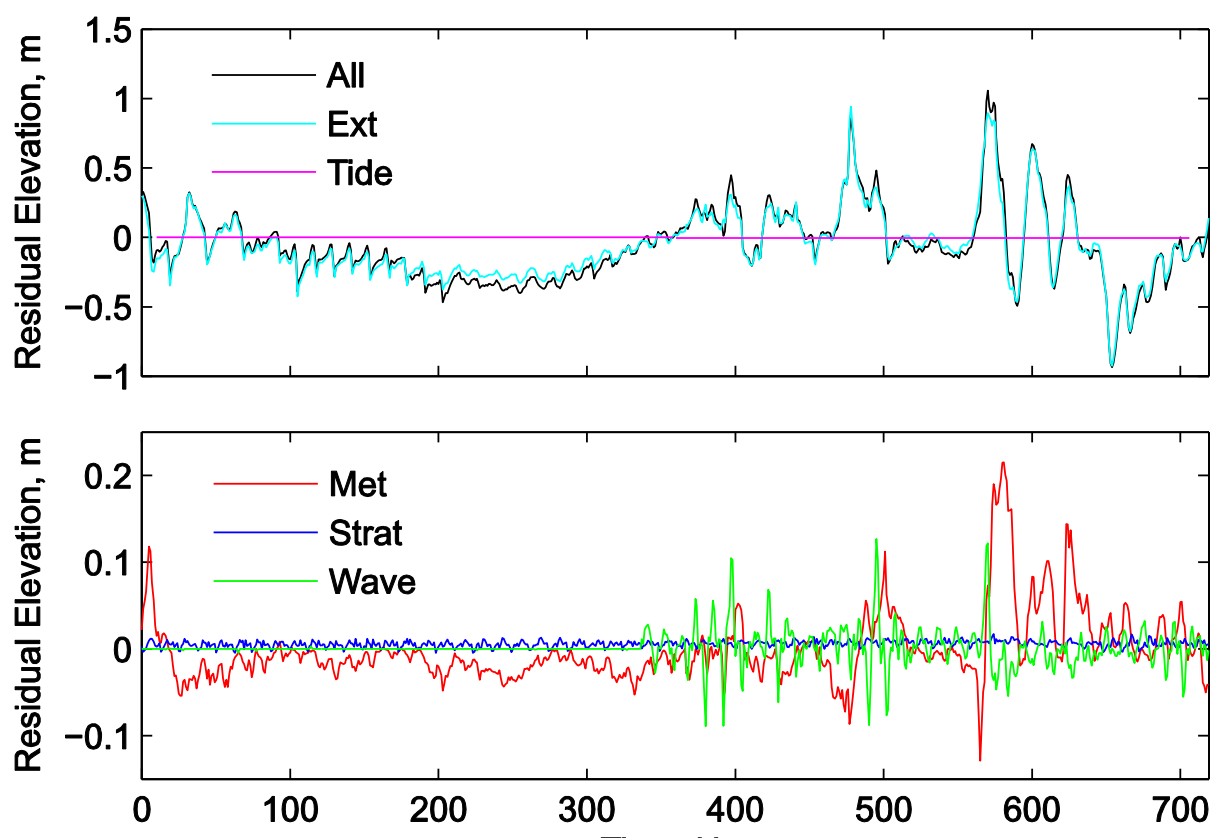

Time, Hrs

386 Figure 4. The Welsh Channel residual elevation generated by the following modelled component process:

387 tides (magenta line), external residuals (cyan line), local meteorology (red line), baroclinicity (blue line), 388 and waves (green line). The time starts at 00:00 $6^{\text {th }}$ February. The processes are shown using different $y-$ 389 axis scales to clearly see the time variation. 

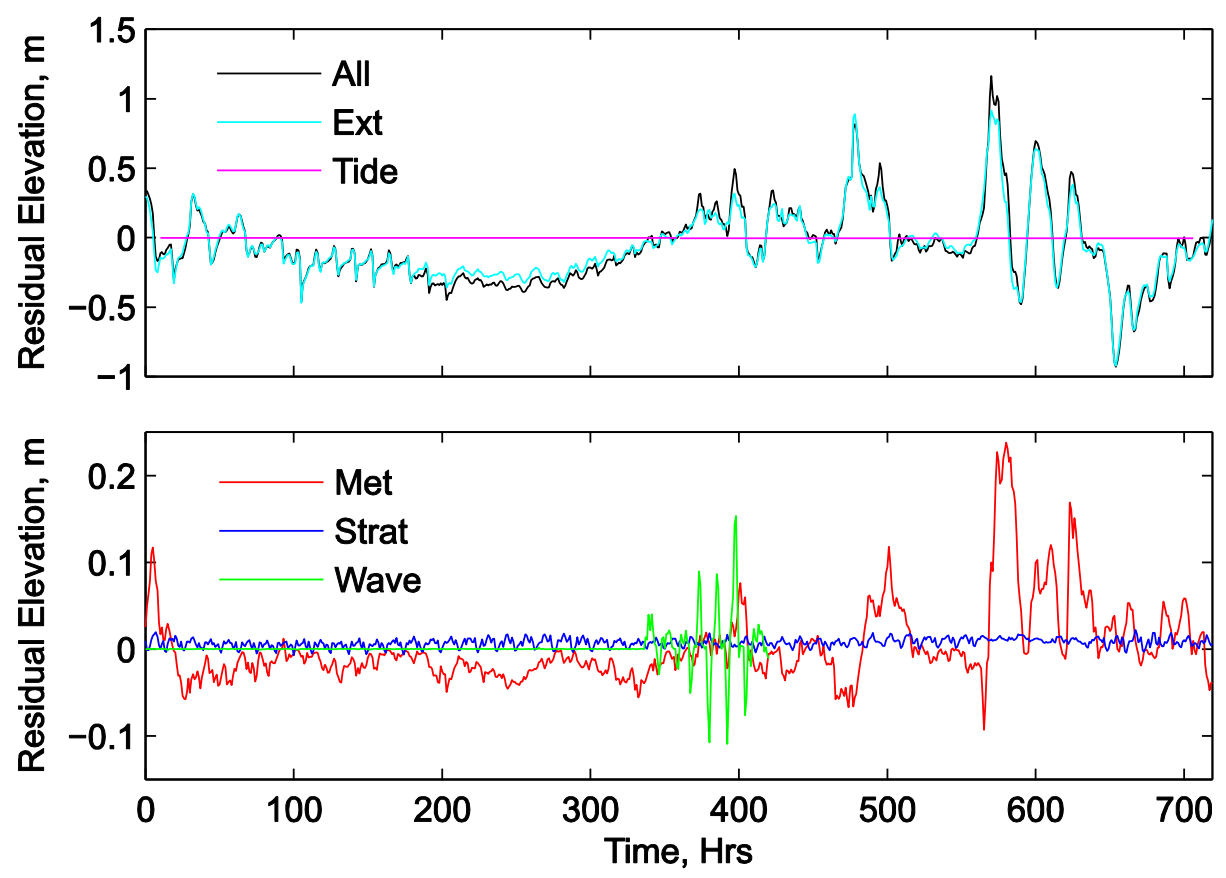

392

Figure 5. As Fig. 4, but for the Hilbre Channel.

393

394 Table 2: The time-averaged residual elevation at the study location in the Welsh and Hilbre Channels.

395 The RMS difference representing the process contribution (Met, Baroc, Wave, Ext, Tide) to the overall residual (All) is given in brackets.

\begin{tabular}{|l|l|c|c|c|}
\hline & Process & $\begin{array}{c}\text { Total period } \\
\text { residual, } \mathrm{m}\end{array}$ & $\begin{array}{c}\text { Calm period } \\
\text { residual, } \mathrm{m}\end{array}$ & $\begin{array}{c}\text { Stormy period } \\
\text { residual, } \mathrm{m}\end{array}$ \\
\hline Welsh Channel & & & & -0.16 \\
\hline & All & -0.07 & -0.03 \\
\hline & Met & $-0.00(0.27)$ & $-0.02(0.21)$ & $0.01(0.31)$ \\
\hline & Baroc & $0.01(0.28)$ & $0.00(0.23)$ & $0.01(0.32)$ \\
\hline & Wave & - & - & $0.00(0.31)$ \\
\hline & Ext & $-0.06(0.05)$ & $-0.15(0.05)$ & $0.02(0.05)$ \\
\hline & Tide & $-0.00(2.34)$ & $-0.01(3.03)$ & $-0.00(1.27)$ \\
\hline Hilbre Channel & & & & \\
\hline & All & -0.07 & -0.17 & 0.04 \\
\hline & Met & $0.00(0.27)$ & $-0.02(0.21)$ & $0.02(0.31)$ \\
\hline & Baroc & $0.01(0.28)$ & $0.01(0.23)$ & $0.01(0.32)$ \\
\hline & Wave & - & - & $0.00(0.32)$ \\
\hline & Ext & $-0.06(0.05)$ & $-0.15(0.04)$ & $0.02(0.06)$ \\
\hline & Tide & $-0.01(2.52)$ & $-0.01(3.21)$ & $-0.00(1.51)$ \\
\hline
\end{tabular}

397

398

399

400

Residual circulation during the calm current-dominant period 
401 The overall residual circulation in the Welsh and Hilbre Channels is quite different between the channels

402 during the initial 15-day calm period. The Welsh Channel residual is dominated by tidal processes and the

403 Hilbre Channel by baroclinic processes, as initially shown by Bolaños et al. (2013). Since the wave model

404 is not applied during this time there is no wave residual generated. However, the wave subplots are 405 shown in the following figures for completeness to enable easy process comparison with the later figures 406 during the stormy and full period analysis. In both channels for both residual current components the local 407 meteorology and external processes have negligible influence (Fig. 6, panel c, d, i and j). The Welsh 408 along-channel residual current component shows that the tide (Fig. 6, panel $\mathrm{k}$ and I) creates the strongest 409 residual component with seaward flow on the right side of the Welsh Channel and landward flow on the 410 left. Along the channel, variation is also seen with flow reversal over the deepest point of the channel. 411 Baroclinicity has a clear and important influence creating a vertical 2-layer structure modifying the tidal 412 residual (Fig. 6, panel e and f). The baroclinicity generates a seaward surface flow and landward bottom 413 flow. The surface layer is slightly deeper towards the left of the channel becoming shallower before 414 disappearing towards the right of the channel.

415 

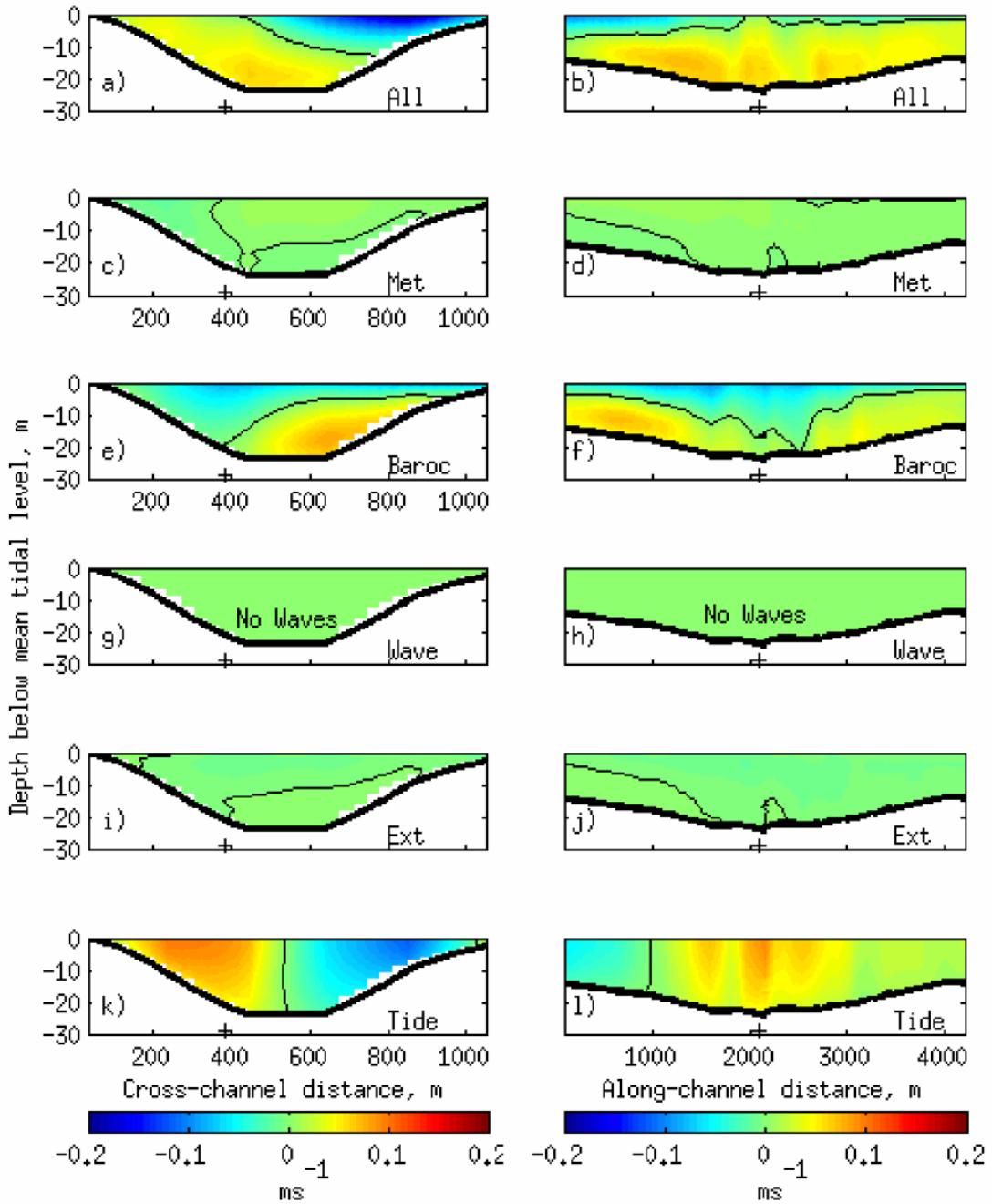

Figure 6. The along-channel residual circulation component in the Welsh Channel, generated by the

following modelled process for the calm period: all (panel a \& b), local meteorology (panel c \& d), baroclinicity (panel e \& f), waves (panel $g$ \& $\mathrm{h}$ for consistency with the later figures), external residuals

420 (panel i \& j) and tides (panel k \& I). The residual is defined as the time-averaged current over the calm

421 study period 00:00 $6^{\text {th }}$ February to $23: 0020^{\text {th }}$ February and is shown for the cross- (left) and along- (right)

422 channel transects. Positive colours represent seaward flow and the black contour represents zero flow.

423 The ' + ' at the bottom of each panel axis shows the point of intersection of the along- and cross-channel transects.

426 The cross-channel residual current component shows the same pattern of tidal dominance (Fig. 7, panel

$427 \mathrm{k}$ and I), with baroclinicity having an important secondary influence (Fig. 7, panel e and f). The tide 428 creates a horizontal 2-layer structure while the baroclinicity creates a vertical 2-layer structure. The tide 
causes flow convergence along the centre of the channel. The baroclinicity causes a surface flow towards the left and a bottom flow towards the right. The two structures combine to give a 2-layer structure with

431 flow reversal occurring along a diagonal from left of centre at the surface to right of centre near the bed

432 (Figure 7a). For both the along- and cross-channel components the cross-channel profile is the same 433 along the channel length. Towards the sea the Welsh Channel curves towards the west, so the profile line 434 analysed becomes closer to the right bank, thus the tidal profile changes colour as it moves from 435 depicting the flow at the centre of the channel to depicting the flow structure along the right side of the 436 channel.
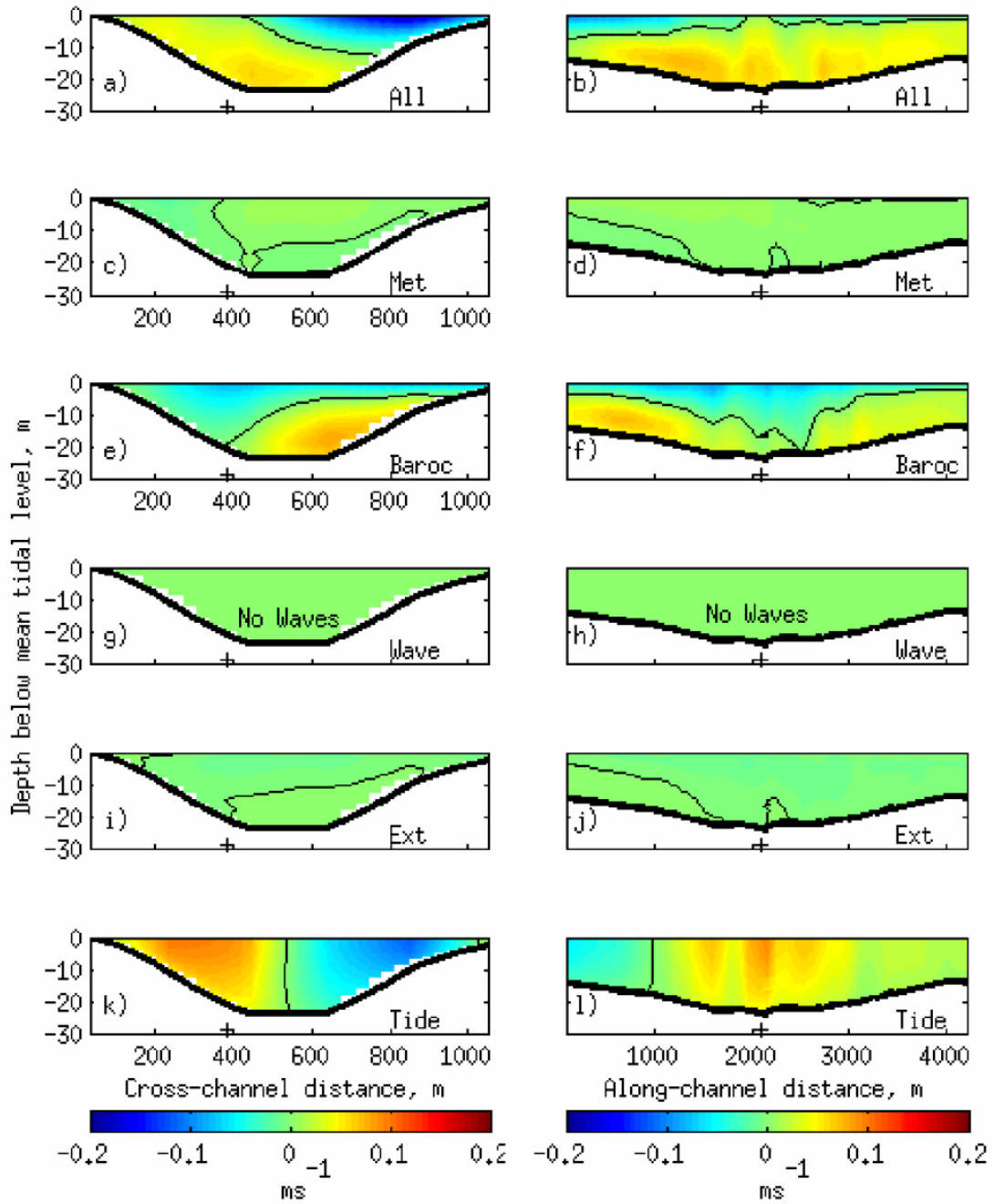

Figure 7. The cross-channel residual circulation component in the Welsh Channel, generated by the following modelled process for the calm period: all (panel a \& b), local meteorology (panel c \& d), baroclinicity (panel e \& f), waves (panel $g$ \& $h$ for consistency with the later figures), external residuals 
442 (panel i \& j) and tides (panel k \& I). The residual is defined as the time-averaged current over the calm 443 study period 00:00 $6^{\text {th }}$ February to $23: 0020^{\text {th }}$ February and is shown for the cross- (left) and along- (right)

444 channel transects. Positive colours represent flow from left to right across the channel when looking along 445 it towards the sea and the black contour represents zero flow. The ' + ' at the bottom of each panel axis shows the point of intersection of the along- and cross-channel transects.

447

448 The Hilbre Channel displays the same 2-layer process induced structures as the Welsh Channel. 449 However, the tidal influence is much weaker (Fig. 8, panel $\mathrm{k}$ and I) and the baroclinicity much stronger 450 (Fig. 8, panel e and f). The combined effect in the along-channel residual current component (Fig. 8a) is 451 to create a vertically-sheared overall residual flow in this channel, compared with a diagonal pattern in the 452 sheared flow within the Welsh Channel (Fig. 6a). The Hilbre cross-channel residual current component 453 (Fig. 9) has a similar shear structure to the Welsh Channel, although, the flow direction is reversed. The 454 tidally generated residual (Fig. 6, panel k and I) is also weaker enabling the stronger baroclinic residual to 455 dominate creating a vertical 2-layer structure in the overall residual circulation pattern. The eastward 456 curvature of the Hilbre Channel causes the straight along-channel transect to initially start closer to the 457 left bank, when facing toward the sea, tending towards the right back with distance towards the mouth. 458 Again, the tidal along-channel residual current profile changes with distance along the channel, due to the 459 profile cutting across the axis of flow reversal. 

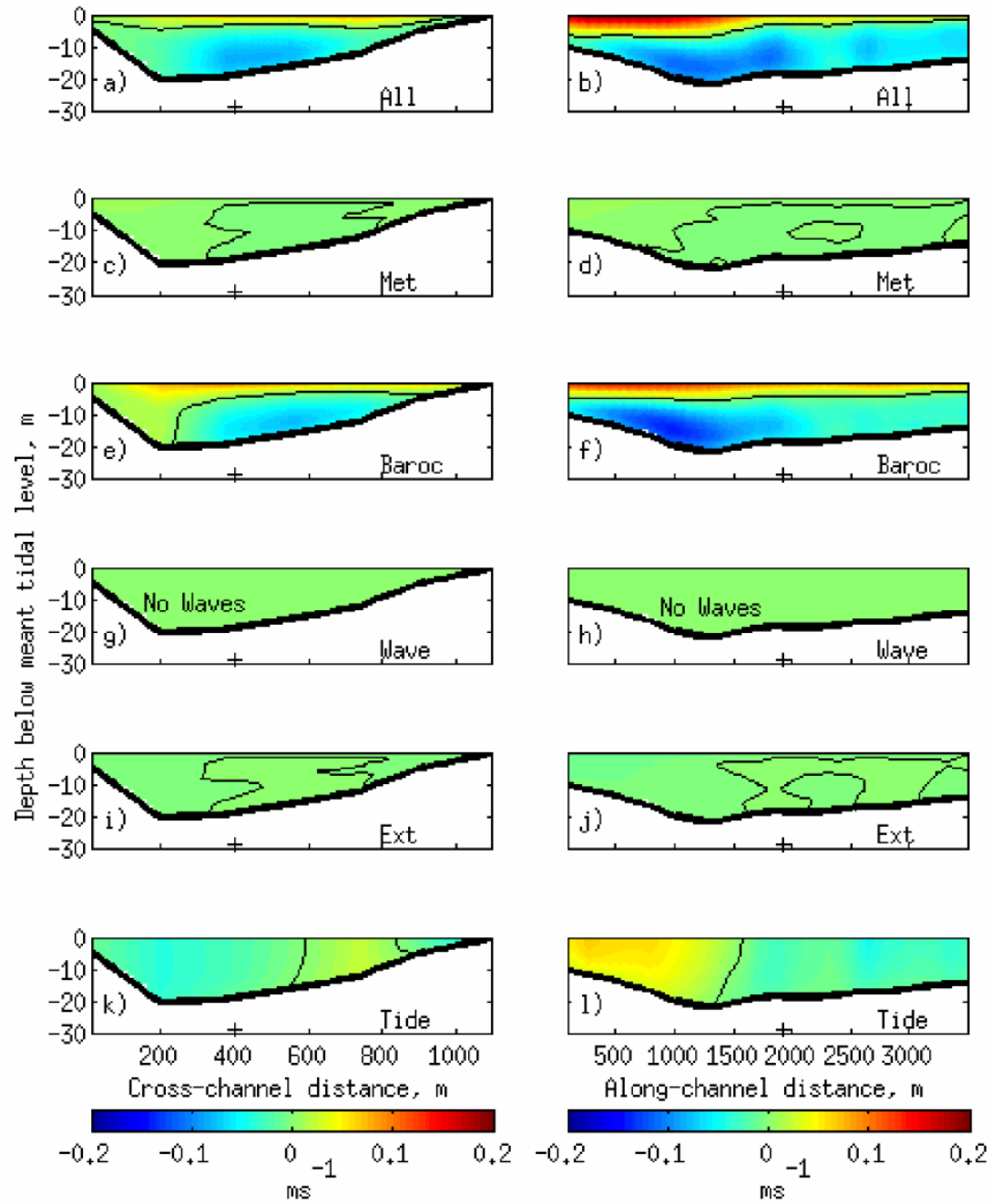

Figure 8. As Fig. 6, but for the Hilbre Channel. 

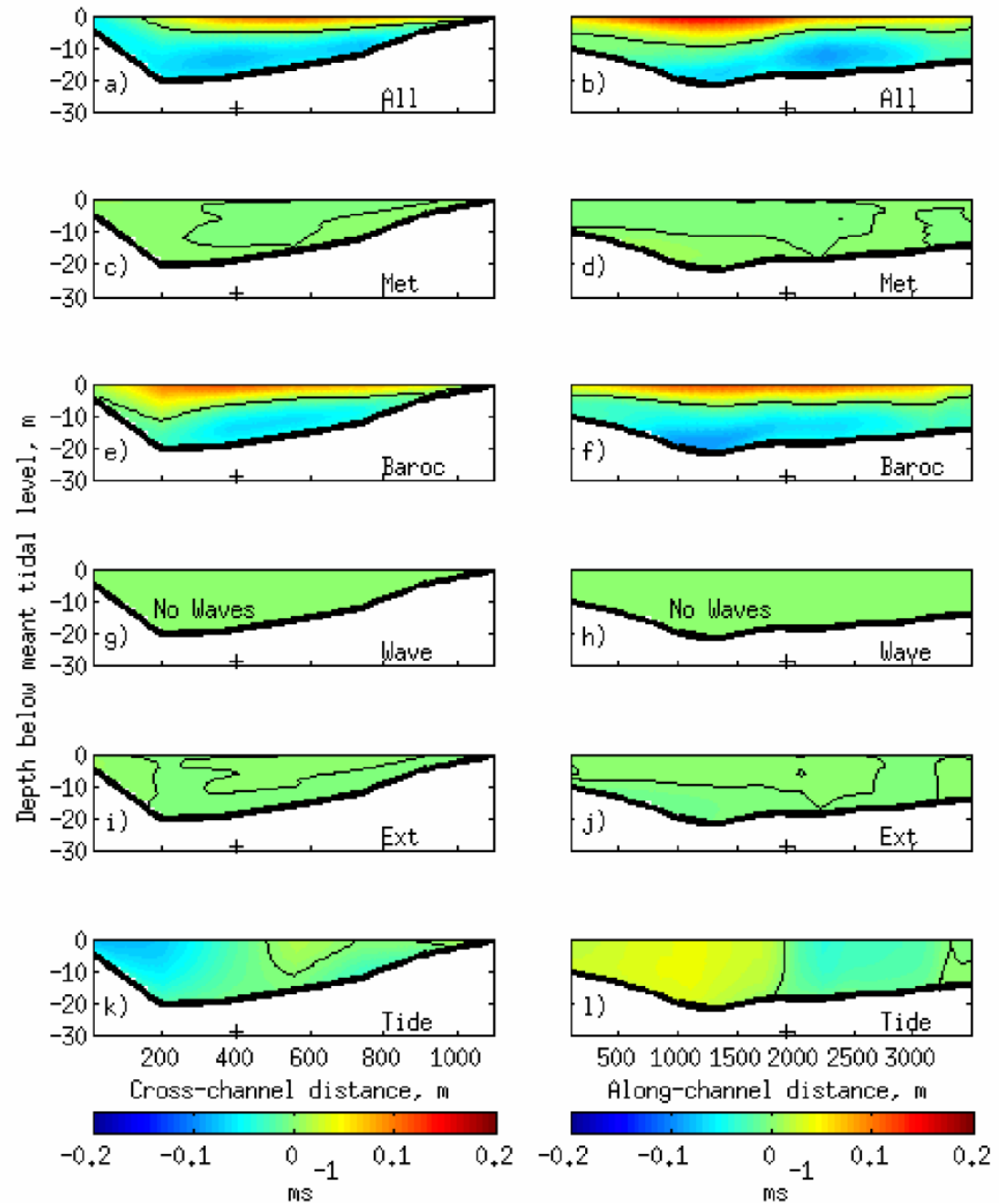

Figure 9. As Fig. 7, but for the Hilbre Channel.

465 By calculating the RMS difference between each process and the total residual circulation it is clear that the Welsh Channel (Table 3) is dominated by tidal processes and the Hilbre Channel (Table 4) by

467 baroclinic processes, as found by Bolaños et al. (2013). In the Welsh Channel baroclinic processes have 468 similar importance to the local meteorology, external processes and waves. In the Hilbre Channel tidal 469 influence is often of secondary importance, except for the along-channel residual current component over

470 the cross-channel transect, where the tide generates a weak residual flow and local meteorology can 471 have a more important affect. In both channels the tide creates a horizontal structure and stratification 472 creates a competing vertical structure. The residual flow direction generated by these processes can be 473 in opposition at points within the presented channel transects. The weaker of these two processes can 474 therefore have a larger RMS difference than the other processes that generate much weaker $\left(< \pm 0.05 \mathrm{~ms}^{-}\right.$ 
$475{ }^{1}$ ) residual flows (e.g. local meteorology), suggesting it contributes less to the overall residual circulation,

476 when really the contribution is in an opposing direction to the overall residual. The RMS difference does

477 not show how the secondary process modifies the primary process to generate the majority of the overall

478 residual circulation. Process interaction within this estuary is known to be equally as important as the

479 subtidal process contribution due to the hypertidal range (Brown et al., Submitted). The RMS difference is

480 therefore also calculated for the tide plus baroclinic processes. In both channels the low value clearly

481 shows how it is the interaction of these processes that typically determines the overall residual circulation,

482 the secondary process weakly modifying the persistent residual circulation of the primary process.

483

484 Table 3: The spatial RMS difference of the along- and cross-current components over the studied channel 485 transects within the Welsh Channel.

\begin{tabular}{|c|c|c|c|c|}
\hline & Process & $\begin{array}{l}\text { Total period } \\
\text { residual, } m\end{array}$ & $\begin{array}{l}\text { Calm period } \\
\text { residual, } m\end{array}$ & $\begin{array}{l}\text { Stormy period } \\
\text { residual, m }\end{array}$ \\
\hline \multicolumn{5}{|l|}{$\begin{array}{c}\text { Cross-channel transect. } \\
\text { Along-channel residual } \\
\text { component }\end{array}$} \\
\hline & Met & 0.08 & 0.09 & 0.08 \\
\hline & Baroc & 0.08 & 0.09 & 0.08 \\
\hline & Wave & 0.08 & - & 0.08 \\
\hline & Ext & 0.09 & 0.09 & 0.08 \\
\hline & Tide & 0.02 & 0.02 & 0.02 \\
\hline & Tide + Baroc & 0.01 & 0.00 & 0.02 \\
\hline \multicolumn{5}{|l|}{$\begin{array}{l}\text { Along-channel transect. } \\
\text { Along-channel residual } \\
\text { component }\end{array}$} \\
\hline & Met & 0.05 & 0.05 & 0.05 \\
\hline & Baroc & 0.05 & 0.05 & 0.05 \\
\hline & Wave & 0.05 & - & 0.04 \\
\hline & Ext & 0.04 & 0.05 & 0.05 \\
\hline & Tide & 0.03 & 0.04 & 0.02 \\
\hline & Tide + Baroc & 0.00 & 0.00 & 0.01 \\
\hline \multicolumn{5}{|l|}{$\begin{array}{c}\text { Cross-channel transect. } \\
\text { Cross-channel residual } \\
\text { component }\end{array}$} \\
\hline & Met & 0.06 & 0.07 & 0.06 \\
\hline & Baroc & 0.06 & 0.06 & 0.06 \\
\hline & Wave & 0.05 & - & 0.05 \\
\hline & Ext & 0.06 & 0.07 & 0.06 \\
\hline & Tide & 0.03 & 0.05 & 0.02 \\
\hline & Tide + Baroc & 0.00 & 0.00 & 0.01 \\
\hline \multicolumn{5}{|l|}{$\begin{array}{l}\text { Along-channel transect. } \\
\text { Cross-channel residual } \\
\text { component }\end{array}$} \\
\hline & Met & 0.04 & 0.04 & 0.04 \\
\hline & Baroc & 0.04 & 0.04 & 0.04 \\
\hline & Wave & 0.04 & - & 0.04 \\
\hline & Ext & 0.04 & 0.05 & 0.03 \\
\hline
\end{tabular}




\begin{tabular}{|l|l|l|l|l|}
\hline & Tide & 0.03 & 0.04 & 0.02 \\
\hline & Tide + Baroc & 0.00 & 0.00 & 0.01 \\
\hline
\end{tabular}

487 Table 4: The spatial RMS difference of the along- and cross-current components over the studied channel transects within the Hilbre Channel.

\begin{tabular}{|c|c|c|c|c|}
\hline & Process & $\begin{array}{l}\text { Total period } \\
\text { residual, } m\end{array}$ & $\begin{array}{l}\text { Calm period } \\
\text { residual, } \mathrm{m}\end{array}$ & $\begin{array}{l}\text { Stormy period } \\
\text { residual, } \mathrm{m}\end{array}$ \\
\hline \multicolumn{5}{|l|}{$\begin{array}{c}\text { Cross-channel transect. } \\
\text { Along-channel residual } \\
\text { component }\end{array}$} \\
\hline & Met & 0.04 & 0.04 & 0.04 \\
\hline & Baroc & 0.02 & 0.02 & 0.02 \\
\hline & Wave & 0.04 & - & 0.04 \\
\hline & Ext & 0.03 & 0.04 & 0.03 \\
\hline & Tide & 0.04 & 0.04 & 0.03 \\
\hline & Tide + Baroc & 0.01 & 0.00 & 0.01 \\
\hline \multicolumn{5}{|l|}{$\begin{array}{c}\text { Along-channel transect. } \\
\text { Along-channel residual } \\
\text { component }\end{array}$} \\
\hline & Met & 0.07 & 0.07 & 0.06 \\
\hline & Baroc & 0.03 & 0.03 & 0.04 \\
\hline & Wave & 0.07 & - & 0.07 \\
\hline & Ext & 0.06 & 0.08 & 0.05 \\
\hline & Tide & 0.06 & 0.07 & 0.05 \\
\hline & Tide + Baroc & 0.01 & 0.00 & 0.02 \\
\hline \multicolumn{5}{|l|}{$\begin{array}{c}\text { Cross-channel transect. } \\
\text { Cross-channel residual } \\
\text { component }\end{array}$} \\
\hline & Met & 0.05 & 0.05 & 0.04 \\
\hline & Baroc & 0.03 & 0.03 & 0.03 \\
\hline & Wave & 0.05 & - & 0.05 \\
\hline & Ext & 0.05 & 0.05 & 0.05 \\
\hline & Tide & 0.04 & 0.05 & 0.03 \\
\hline & Tide + Baroc & 0.01 & 0.00 & 0.01 \\
\hline \multicolumn{5}{|l|}{$\begin{array}{c}\text { Along-channel transect. } \\
\text { Cross-channel residual } \\
\text { component }\end{array}$} \\
\hline & Met & 0.05 & 0.06 & 0.05 \\
\hline & Baroc & 0.02 & 0.02 & 0.02 \\
\hline & Wave & 0.05 & - & 0.04 \\
\hline & Ext & 0.05 & 0.06 & 0.04 \\
\hline & Tide & 0.05 & 0.05 & 0.04 \\
\hline & Tide + Baroc & 0.00 & 0.00 & 0.01 \\
\hline
\end{tabular}

\section{Residual circulation during the stormy wave-current period}

491 During the later 15-day stormy period the overall residual circulation is again quite different between the

492 Welsh and Hilbre Channels. As for the calm period the dominant process in the Welsh Channel residual 493 is the tide (Figs. 10 and 11, panel $\mathrm{k}$ and I) and in the Hilbre Channel it is the baroclinicity (Figs. 12 and 13, 494 panel e and f). The overall storm period residual is very similar to that of the calm period in both channels 
and the tidal residual (Figs. 10-13, panel $\mathrm{k}$ and $\mathrm{I}$ ) is nearly identical, due to both periods consisting of a single spring-neap cycle. By comparing calm with storm periods, the Welsh Channel shows some slight differences at the surface in the structure of the overall along-channel residual circulation component and the Hilbre Channel shows slight differences at the surface in the structure of the overall cross-channel residual circulation component. For the storm period the local meteorology and external processes have more impact on the residual circulation and the enhanced wind and wave mixing weakens the baroclinic

501 influence, more so in the Welsh Channel. In the Welsh Channel the local meteorology and externally502 induced residuals have a 2-layer vertically-sheared structure with opposing process flow directions in the 503 along-channel residual current component (Fig. 10, panel c, d, j and i). This also occurs in the Hilbre 504 Channel but the residual is of weaker magnitude. The local meteorology causes a landward surface flow 505 and seaward bottom flow in the along-channel residual current component in the Welsh Channel (Fig. 10, 506 panel $\mathrm{c}$ and d) and a seaward flow over the majority of the Hilbre Channel (Fig. 12, panel c and d). In the cross-channel residual current component the surface flow is towards the right in the Welsh Channel and 508 left in the Hilbre Channel, with reversed bottom flow (Figs. 11 and 13, panel c and d). The external residual creates a seaward surface flow and landward bottom flow in the along-channel current component (Figs. 10 and 12, panel $\mathrm{i}$ and j). In the Welsh cross-channel residual current component the

511 surface flow is towards the left and the bottom flow is towards the right, while in the Hilbre Channel a 512 central layer flows towards the left with return flow near the bed and surface (Figs. 11 and 13, panel $\mathrm{i}$ and 513 j). The presence of waves enables generation of a wave-induced residual that has similar magnitude to 514 the non-tidal process within the Welsh Channel and the non-baroclinic processes in the Hilbre Channel. 515 The direction of the wave-induced along-channel current residual is opposite in the two channels (Figs. 51610 and 12, panel e and f). In the Welsh Channel it is mainly seaward, with a narrow bottom layer of 517 landward flow. In the Hilbre Channel it creates a landward flow at all depths, with faster velocity away 518 from the bottom and surface boundaries. This wave-induced flow has previously been shown, by Bolaños 519 at al. (Submitted), to improve the modelled net residual circulation when compared with this period of 520 ADCP observation. For the cross-channel wave-induced residual current component the Welsh Channel 521 experiences a general flow towards the left, while the Hilbre Channel has a 2-layer structure in the 522 horizontal with flow towards the centre from both sides. During stormy conditions the residuals induced 523 by storm properties (e.g. waves and wind) increases and the increased turbulent mixing slightly weakens 524 the baroclinicity. However, the storm process importance is still secondary to that of the tide and 

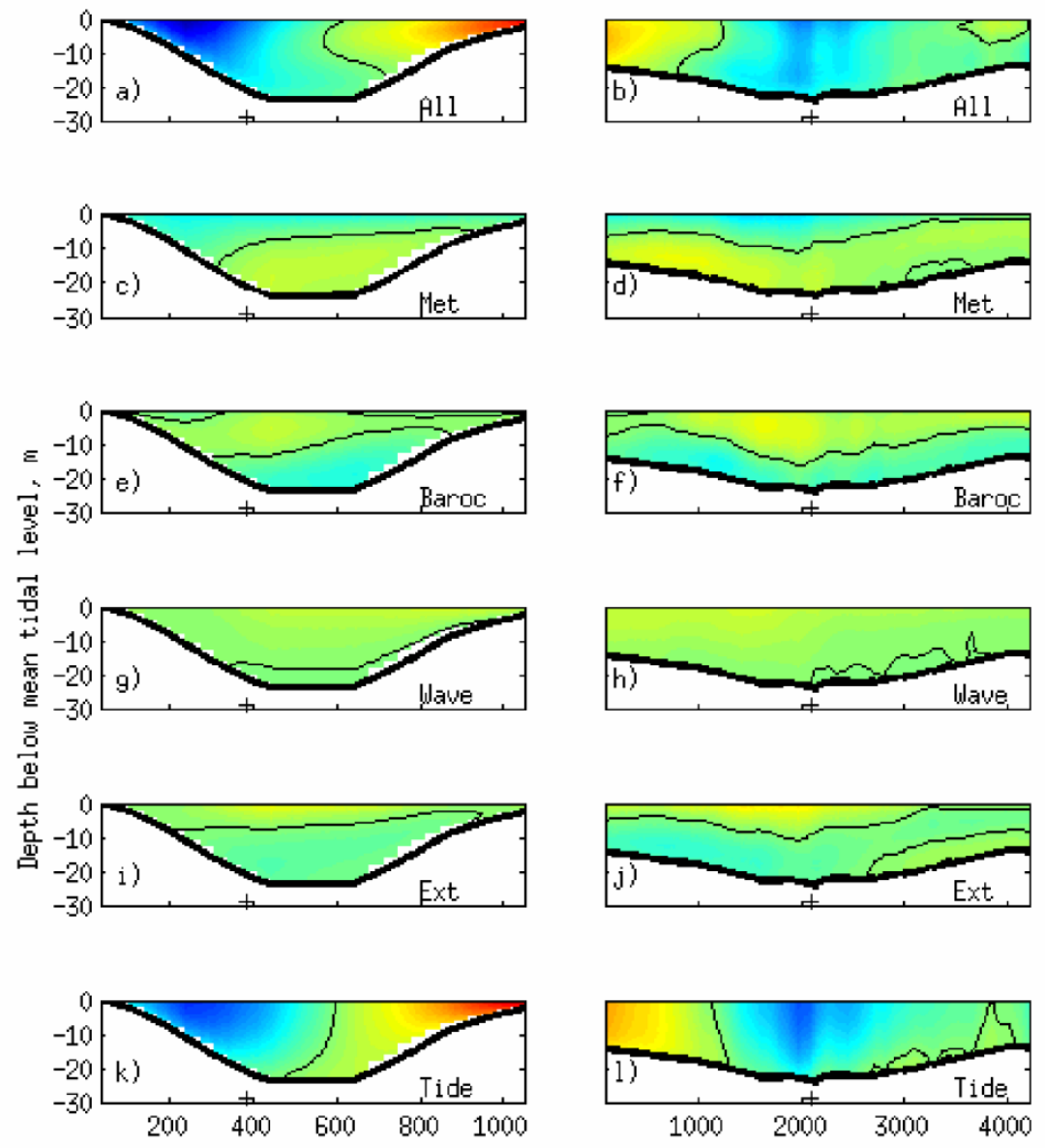

Cross-channel distance, m
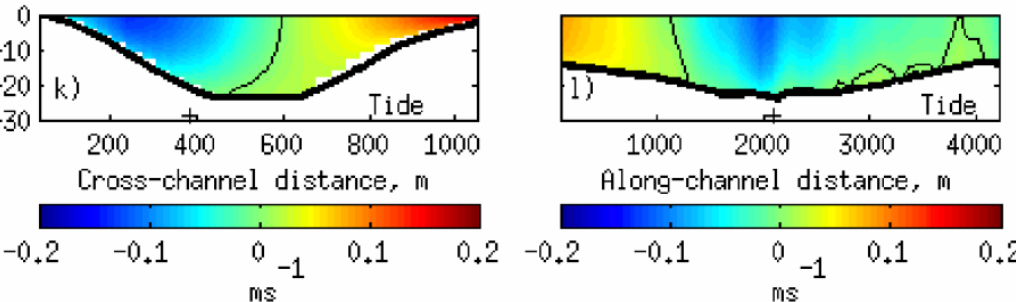

Along-channel distance, $m$

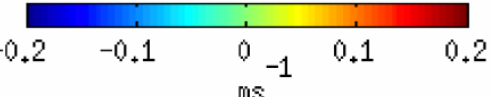

529 Figure 10. The along-channel residual circulation component in the Welsh Channel, generated by the following modelled process for the storm period: all (panel a \& b), local meteorology (panel c \& d),

531 baroclinicity (panel e \& f), waves (panel g \& h), external residuals (panel i \& j) and tides (panel k \& l). The 532 residual is defined as the time-averaged current over the stormy study period 00:00 $21^{\text {th }}$ February to 23:00 $6^{\text {th }}$ March and is shown for the cross- (left) and along- (right) channel transects. Positive colours 534 represent seaward flow and the black contour represents zero flow. The ' + ' at the bottom of each panel axis shows the point of intersection of the along- and cross-channel transects. 

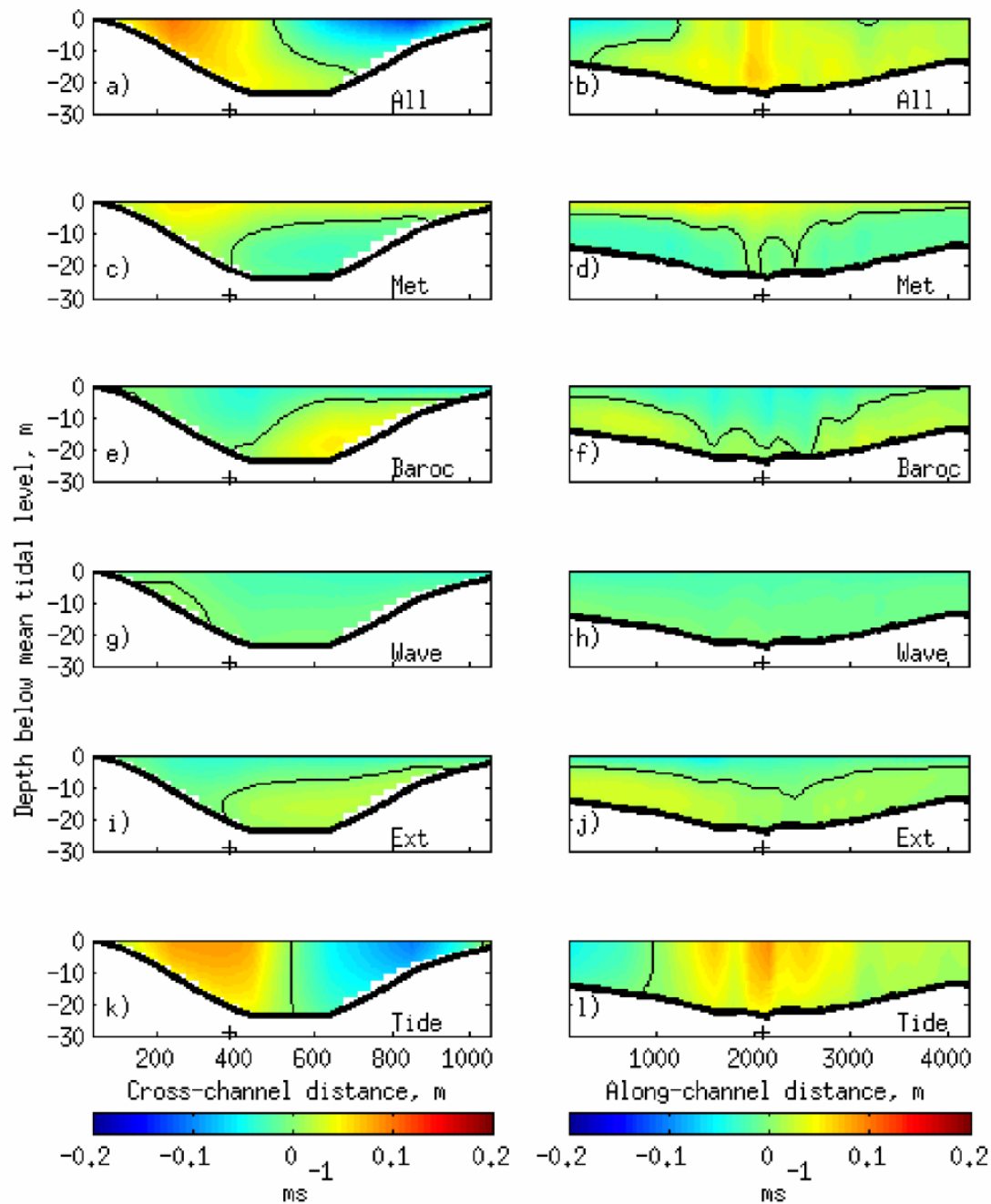

Figure 11. The cross-channel residual circulation component in the Welsh Channel, generated by the

following modelled process for the storm period: all (panel a \& b), local meteorology (panel c \& d),

baroclinicity (panel e \& f), waves (panel g \& h), external residuals (panel i \& j) and tides (panel k \& l). The

541 residual is defined as the time-averaged current over the stormy study period 00:00 $21^{\text {th }}$ February to

$542 \quad 23: 006^{\text {th }}$ March and is shown for the cross- (left) and along- (right) channel transects. Positive colours

543 represent flow from left to right across the channel when looking along it towards the sea and the black

544 contour represents zero flow. The '+' at the bottom of each panel axis shows the point of intersection of 

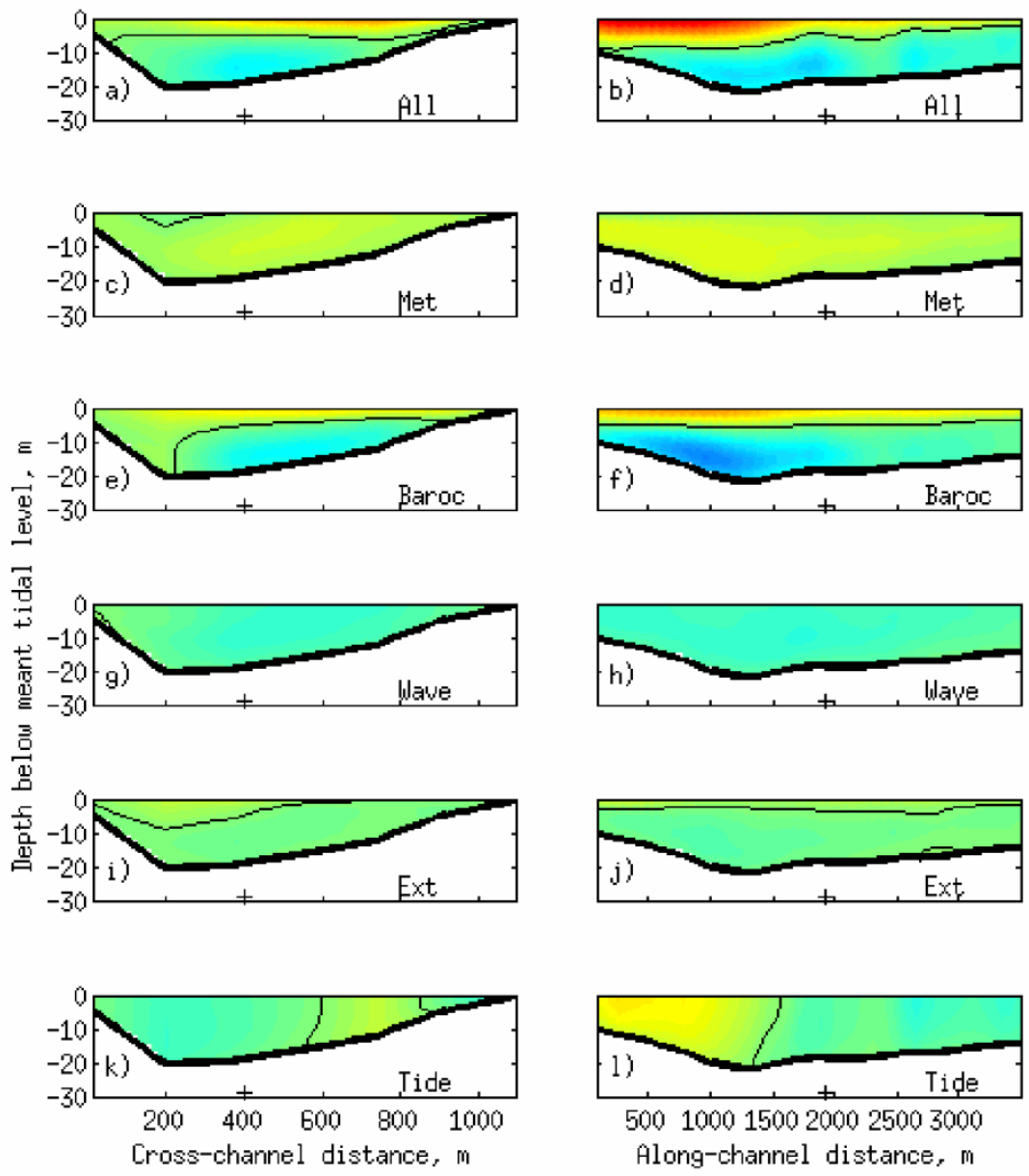

50010001500200025003000

Along-channel distance, m
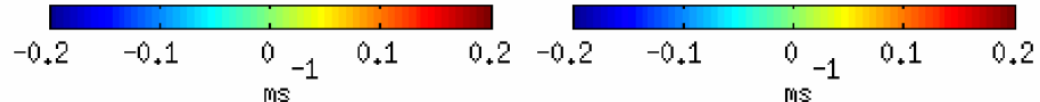

Figure 12. As Fig. 10, but for the Hilbre Channel. 

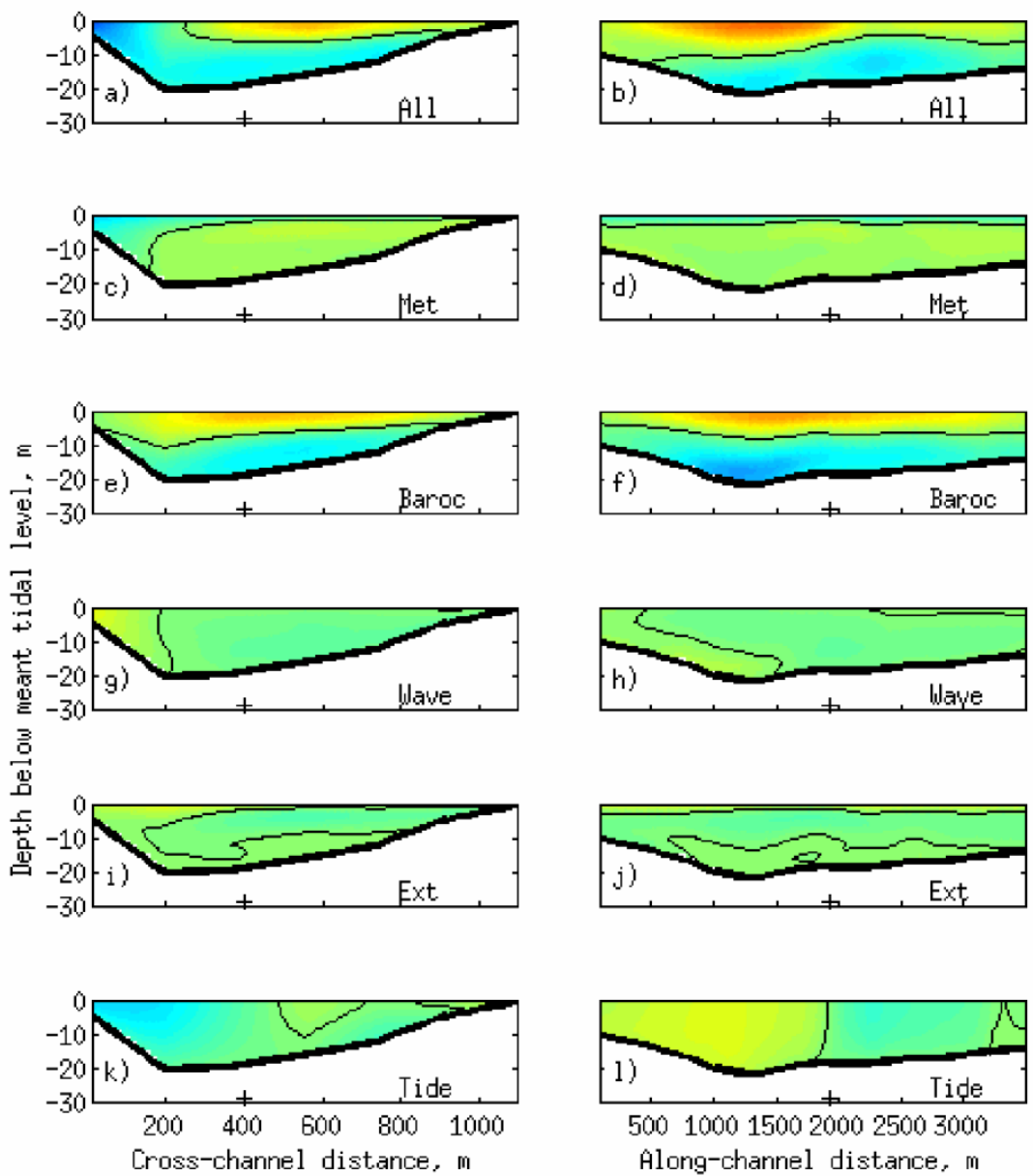

50010001500200025003000

Along-channel distance, $m$

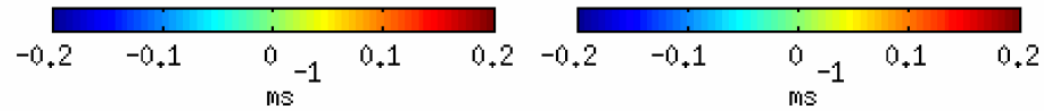

Figure 13. As Fig. 11, but for the Hilbre Channel.

553 The RMS difference from each process during the storm period is very similar to that during the calm

554 period (Table 3 and 4). In some residual components the storm conditions lessen the importance of baroclinicity, strengthening the tidal dominance, but overall, the tide-baroclinic residual current determines

556 the residual circulation within these two channels. Since the storm period residuals are still predominantly

557 driven by non-storm processes within this hypertidal estuary, the long-term residual is unlikely to change

558 significantly as a consequence of future changes in storminess.

\section{Residual circulation during the full (30-day) period}

561 By considering an equal time period of calm and stormy conditions the influences of selected processes can be deduced for the monthly period. Since the storm conditions do not have a significant influence on 
563 the residual circulation, the full 30-day period experiences a relatively constant residual circulation. The 564 time-averaged profiles (Figs. 14-17) are therefore similar to that of the calm conditions. This is mainly due 565 to the hypertidal conditions being dominant in this estuary generating a consistent tidal residual under any 566 atmospheric forcing. However, it is also partly due to the fact that storm influence only slightly weakens 567 the baroclinic residual circulation and that the storm properties only generate a weak residual themselves. 568 This is due to estuarine sheltering from storm impact. The NW-SE alignment is perpendicular to the wind 569 direction, SW-W, associated with extreme surge events. This limits the internal fetches, while banks at 570 the mouth reduce external wave propagation (generated by W-NW wind directions) into the estuary. Over 571 the month long period the strength of the baroclinic residual circulation is slightly weaker than during calm 572 conditions, due to increased turbulent mixing (storms) and changes in river discharge. Due to the local 573 meteorology and external influence having nearly negligible impact during the calm period and some, all 574 be it weak, impact during the storm period the 30-day profiles for these processes are similar to the 15575 day storm profiles with slightly weaker magnitudes. The wave induced residual circulation over the 30576 day period is that of the 15-day storm profile because they were not modelled, as they were considered 577 negligible, during the calm period. Since the storm influence is weak in magnitude it is therefore likely that 578 the long-term (annual) residual profile will be influenced by the cumulative duration of calm and storm 579 periods. The long-term (annual) profile is unlikely to differ significantly from the the 15-day calm period 580 profiles. Storm events seem to have low impact on this estuary and the annual cumulative duration of 581 significant storm events is unlikely to exceed the cumulative duration of calm periods, at present. The 582 vertical time-varying residual profile during a storm event is looked at by Brown et al. (submitted) and has 583 more noticeable impact at the short-term event scale. However, its influence is shown here to average out 584 over the 30-day period when considering the residual circulation. 

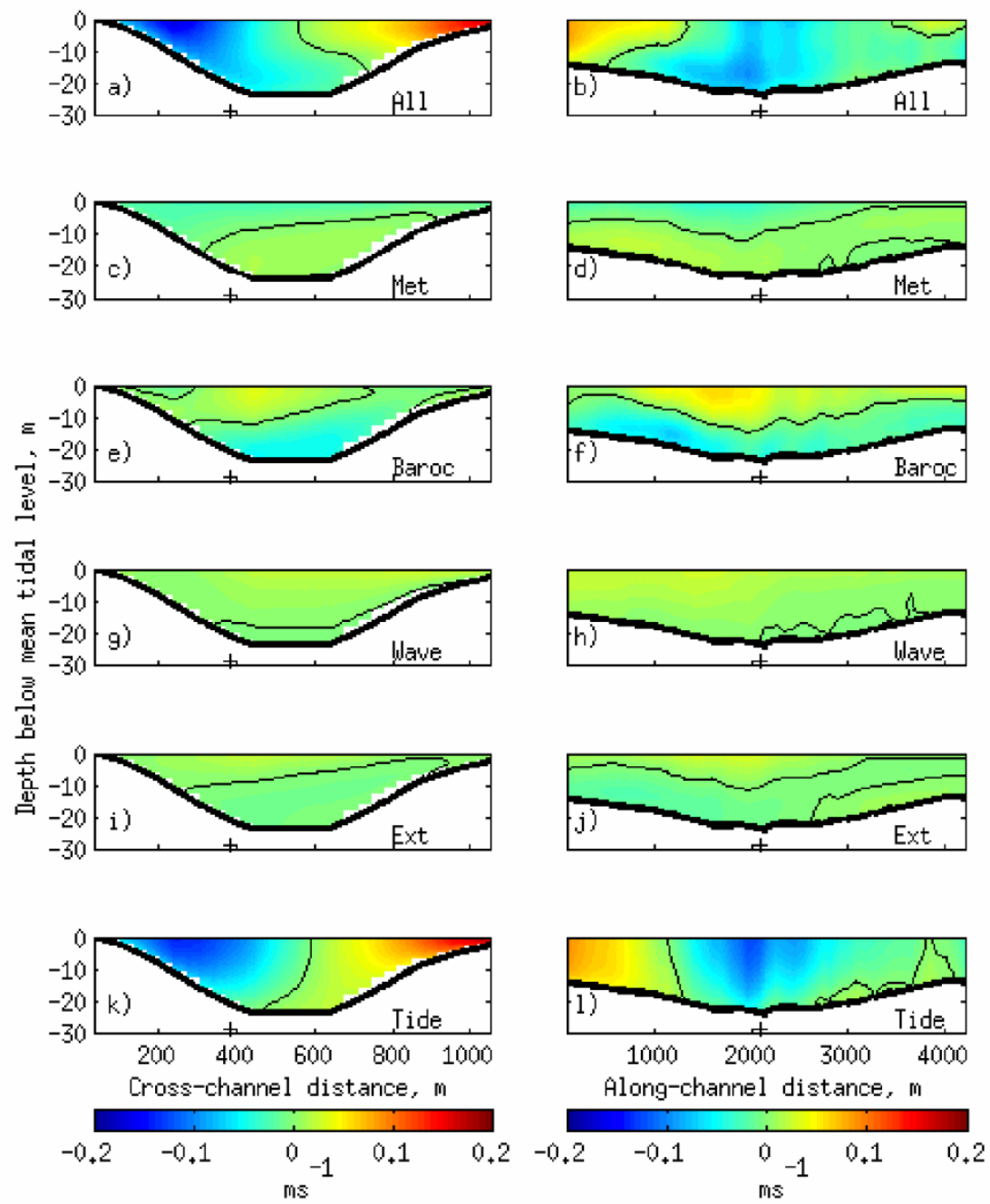

587 Figure 14. The along-channel residual circulation component in the Welsh Channel, generated by the 588 following modelled process for the full period: all (panel a \& b), local meteorology (panel c \& d), 589 baroclinicity (panel e \& f), waves (panel g \& h), external residuals (panel i \& j) and tides (panel k \& l). The 590 residual is defined as the time-averaged current over the full study period 00:00 $6^{\text {th }}$ February to $23: 006^{\text {th }}$ 591 March and is shown for the cross- (left) and along- (right) channel transects. Positive colours represent seaward flow and the black contour represents zero flow. The ' + ' at the bottom of each panel axis shows the point of intersection of the along- and cross-channel transects. 

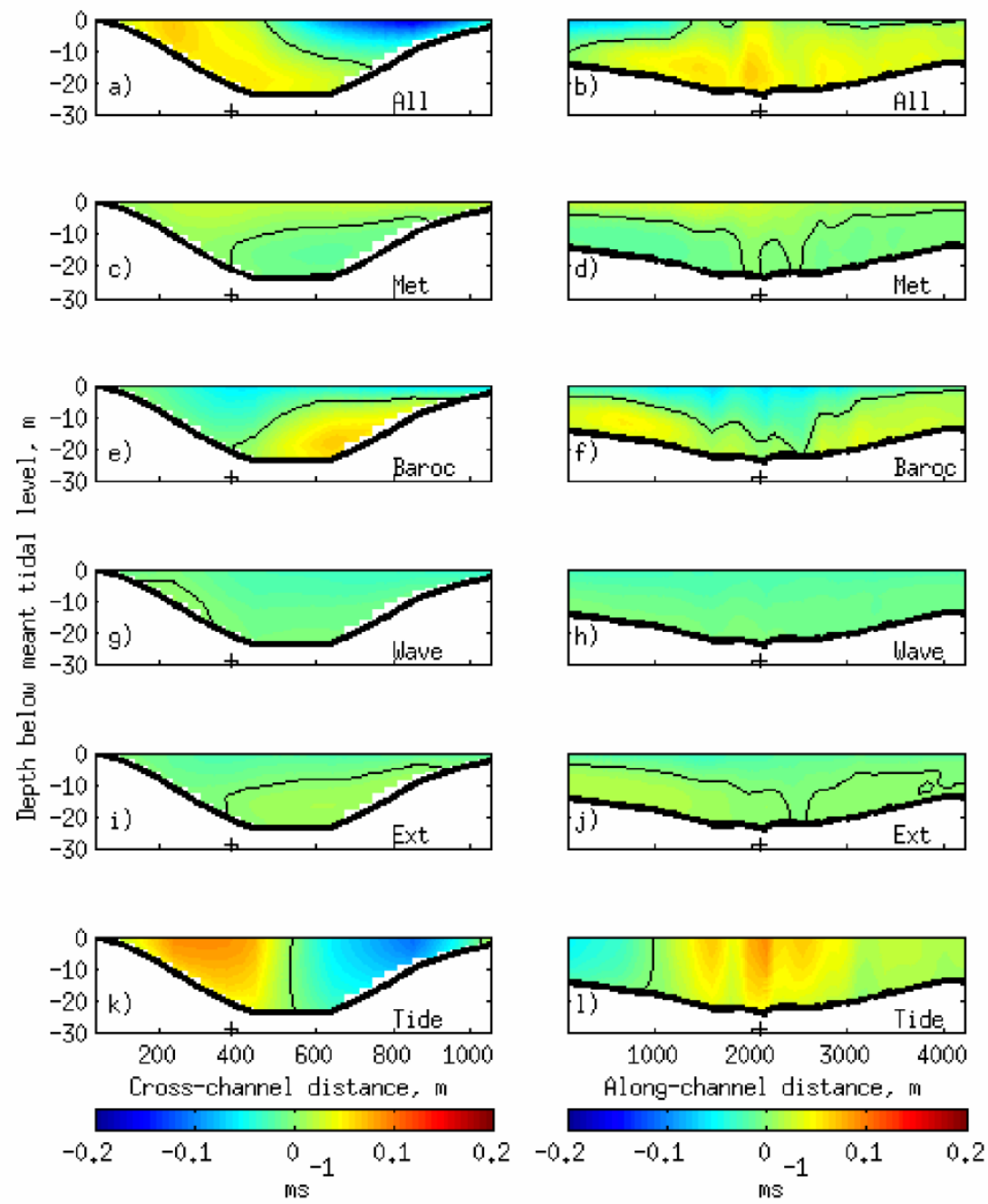

Figure 15. The cross-channel residual circulation component in the Welsh Channel, generated by the following modelled process for the full period: all (panel a \& b), local meteorology (panel c \& d),

598 baroclinicity (panel e \& f), waves (panel g \& h), external residuals (panel i \& j) and tides (panel k \& I). The 599 residual is defined as the time-averaged current over the full study period 00:00 $6^{\text {th }}$ February to $23: 006^{\text {th }}$ 600 March and is shown for the cross- (left) and along- (right) channel transects. Positive colours represent flow from left to right across the channel when looking along it towards the sea and the black contour represents zero flow. The ' + ' at the bottom of each panel axis shows the point of intersection of the alongand cross-channel transects. 

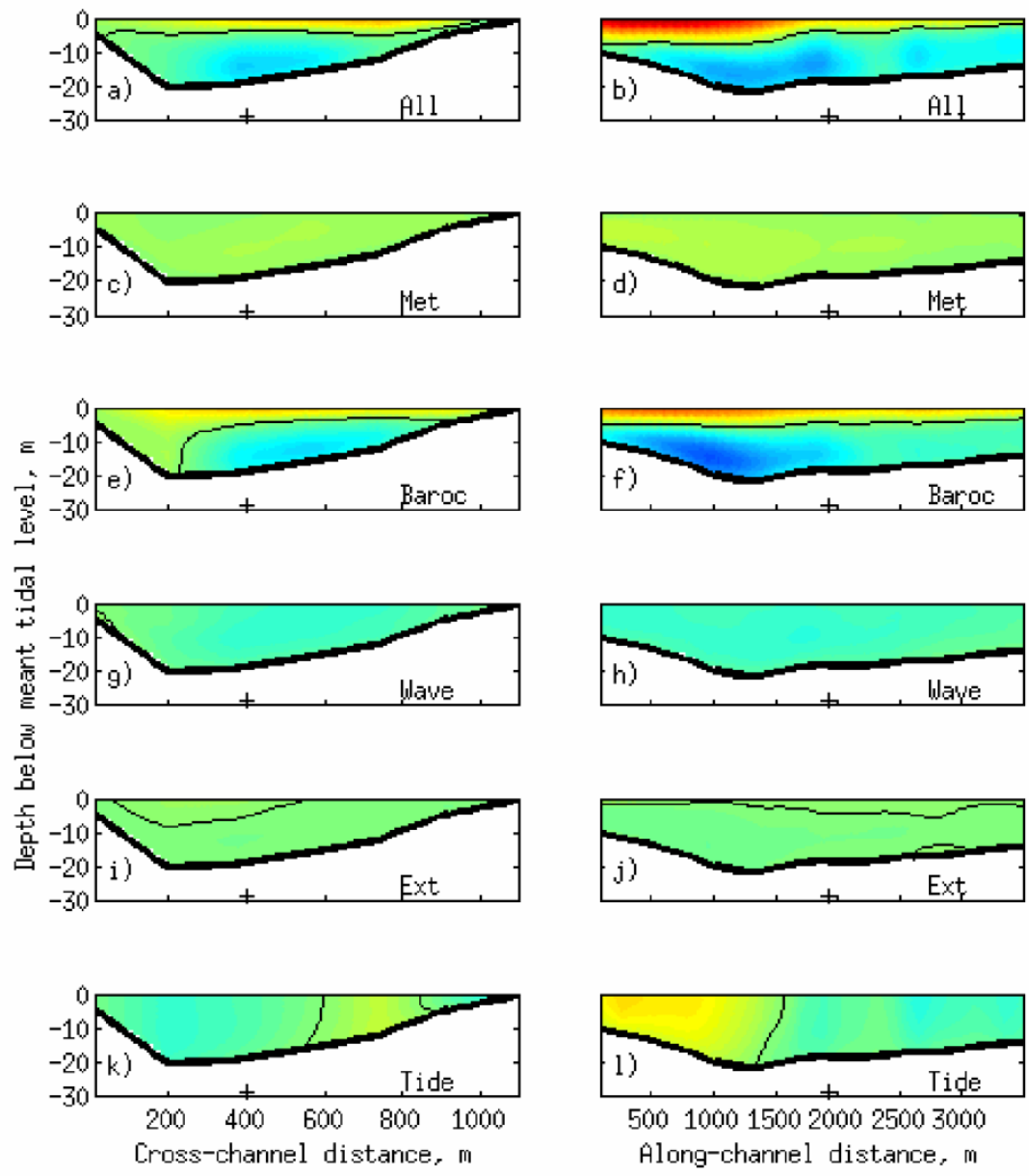

50010001500200025003000

Along-channel distance, m

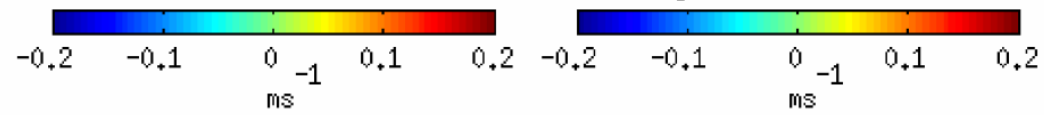

Figure 16. As Fig. 14, but for the Hilbre Channel. 

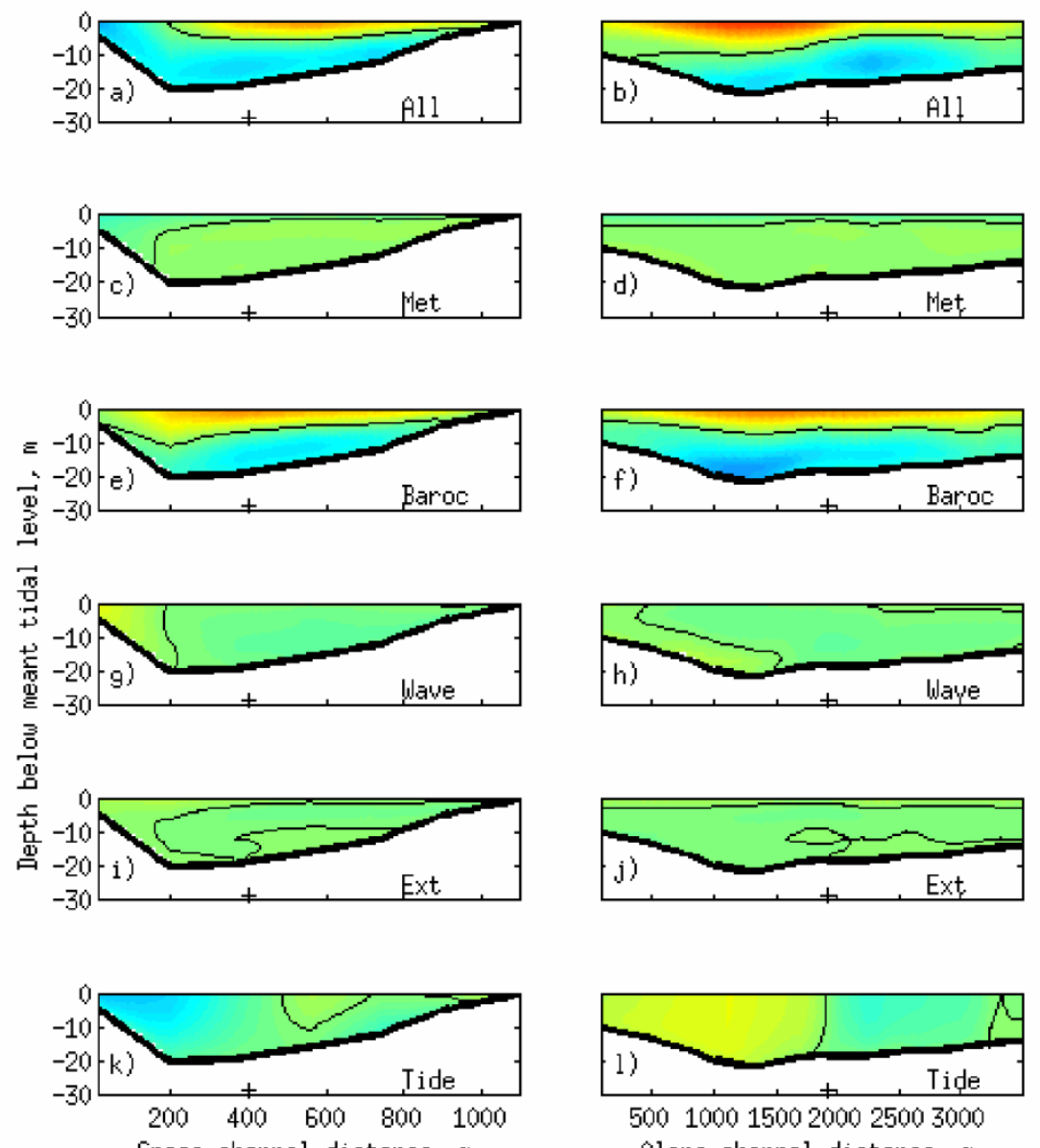

Cross-channel distance, m

Along-channel distanoes m

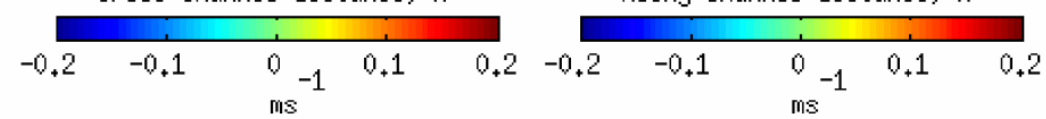

Figure 17. As Fig. 15, but for the Hilbre Channel.

\section{Discussion}

612 A barotropic-baroclinic-wave model has been used to study selected process contribution to the 30-day

613 residual elevation and residual circulation. The Eulerian residual circulation is presented for each process

614 to identify the order of their importance. To calculate the full residual mass transport the Lagrangian time-

615 average also needs consideration to account for Stokes' drift (see Giddings et al., 2013). Here, results are

616 presented for a tidally-dominant and baroclinically-dominant channel close to the mouth of a hypertidal

617 estuary, the Dee. This extends the study of Bolaños et al. (2013) to determine how equal periods of calm

618 and wavy conditions combine to influence the monthly time-averaged residual. The time-varying (event

619 scale) process contributions are shown by Brown et al. (Submitted). It is clear that during events the 620 vertical profile in residual circulation can be very different to the time-averaged profile. For particle 
621 transport this may be important as the magnitude of transport during short-period events (e.g. storms)

622 may be significant. At the studied locations the mean 30-day tide alone along-channel residual circulation

623 averaged over the cross-channel transect indicates that overall the Welsh Channel is flood-dominant and

624 the Hilbre Channel is ebb-dominant. This flood/ebb-dominance is important, greatly influencing the 625 channels' residual circulation. The nearshore salinity field and tidal conditions have greater influence on 626 the flood-dominant Welsh Channel (higher salinities and tidally-dominant) and the up estuary riverine 627 conditions have greater influence on the ebb-dominant Hilbre Channel (lower salinities and baroclinicly628 dominant). In both channels the residual elevation is mainly controlled by external processes to the 629 estuary and local meteorology, while the combined effect of local tide and baroclinicity determines the 2D 630 residual circulation. In the Welsh Channel the tide is the most important process and in the Hilbre 631 Channel baroclinic processes dominate (Bolaños et al., 2013). The horizontal Richardson numbers 632 suggest the channels experience tidal straining, which influences the residual circulation, this is in accord with these results. Although the Wedderburn number suggests wind is important for mixing, our findings, 634 in agreement with Bolaños et al. (2013), show that this process has little influence on the time-averaged 635 baroclinic residual circulation. The Ekman number calculated by Bolaños et al. (2013) correctly predicts horizontal shear in both channels, as seen in the along-channel tidal residual circulation (particularly in

637 the Welsh Channel) in agreement with that described by Winant (2008). During storm conditions the 638 residual elevation is significantly influenced by the storm processes (external surge, wind and waves), 639 while the residual circulation is only slightly modified. During calm conditions the residual water level 640 varies, but not to the extent of that during storm conditions. Compared with the variation in the tidal range $641(<10 \mathrm{~m})$ together with the fact the surge peaks often avoid high water (Proudman, 1957; Rossiter, 1961; 642 Horsburgh and Wilson, 2007), the total water depth within the estuary rarely differs from the maximum 643 spring tide conditions. Wave effects are as important as the local meteorology and external influences at 644 the study locations. However, these storm properties have limited impact on the residual circulation, but 645 are all required for accurate modelling of the residual circulation (Bolaños et al., submitted).

647 Even though this estuary is hypertidal and has a low river input, baroclinicity is an important process in 648 both channels; dominating the residual circulation in the Hilbre Channel (with weak tidal residual) and 649 modifying the strong tidal residual in the Welsh Channel. Baroclinicity is greater in the Hilbre Channel due 650 to the Coriolis Effect (Brown et al., Submitted) diverting the freshwater flow towards this channel. Tidal 
dominance within the channels, which is also likely to be a consequence of the Coriolis Effect, also

652 facilitates freshwater flow within the Hilbre Channel promoting baroclinicity, while inhibiting it in the Welsh

653 Channel. The barocilnic influence remains fairly constant over time even though the mean river discharge

654 is greater during the calm than the stormy period. The strength of the tidal residual circulation is near zero 655 over the spring-neap cycle, but short-term variation is related to shallow water effects and is complicated by the time-varying channel geometry.

The weaker freshwater inflow (27\% less during the stormy period than the calm period) combined with increased mixing under storm conditions does not significantly reduce the strength of the baroclinic residual, as seen in Figures 8 and 9 compared with Figures 12 and 13. The horizontal Richardson

661 number for these channels (calm period: Hilbre Channel $=1.2$, Welsh Channel $=0.84$; storm period: 662 Hilbre Channel $=0.84$, Welsh Channel $=0.56)$ is consistent for tidal straining $(>0.25)$. During these 663 periods the horizontal Richardson number is always slightly greater in the Hilbre Channel, suggesting 664 stronger straining and therefore greater baroclinic influence. In calm conditions the value tends towards 665 the threshold for permanent stratification (O1), especially within the Hilbre Channel. Although the increase 666 in turbulent mixing reduces the values during stormy conditions, the channels still remains in a regime of 667 tidal straining. These channels are therefore likely to always be tidally strained and the baroclinic contribution is likely to be persistent. The reduced river discharge during the storm period may cause the reduced variability in the baroclinic residual elevation during this time. Future changes in temperature, 670 salinity and river flow could influence the strength and therefore importance of the baroclinicity, especially 671 in the Hilbre Channel. The difference in dominant processes between the studied channels suggests any 672 change will not have equal influence across the estuary.

674 At present coastal storm impact has minor influence on the overall current residual within this estuary; the wave-circulation conditions look very similar to that of the calm conditions when comparing equal periods 676 of 15 days. The long-term residual circulation is therefore likely to be similar to that of the full (30-day) 677 study period. Increased storminess could shift the residual circulation towards that of the storm period. 678 The tide dominated Welsh Channel residual is unlikely to change; while the Hilbre Channel could possibly 679 become more tide dominant, due to increased turbulent mixing. Changes in offshore storminess will have 680 more noticeable impact on the residual elevation, as storm processes are the major contributor, than the 
residual circulation. Although little change in future storm conditions are suggested for Liverpool Bay

682 (Brown et al., 2012b), sea level rise may modify coastal tidal dynamics and wave conditions, through changes in inundated areas, depth and consequent morphological evolution. This has the potential to modify the tidal interaction and the tidal residual, which is important in hypertidal estuaries.

The difference between the (tidal) Welsh and (baroclinic) Hilbre Channel residual circulation

687 demonstrates: that although the same tidal regime (hytertidal conditions) is experienced by both 688 channels, tidal or baroclinic processes may dominate the residual circulation within a particular channel, and it cannot be assumed that under a given tidal characteristics that the tide will (macro or hypertidal condition) or will not (microtidal conditions) determine the dominant process in creating the residual flow 691 within a channel. The strength of the baroclinic processes and their persistence during storm conditions 692 suggests they are likely to influence the long-term residual circulation no matter how energetic the conditions. This poses the question: Is the baroclinic circulation in a hypertidal estuary dominated by the 694 processes related to tidal straining or the horizontal density gradient? Factors that will influence the 695 importance of the baroclinicity will be how sheltered an estuary channel is from storm impact and the strength of the tidal residual. The baroclincly dominant channel is likely to have more variable residual over an annual period than a tidally dominant channel due to the fluctuating seasonal nature of storms and freshwater input.

The modelling system used here is considered to give valid results for the Dee Estuary and has been used to determine the 30-day process contribution to the estuarine residuals. Although 3D modelling provides a robust method for isolating process contribution, while incorporating nonlinear interactions, discrepancies between the real (highly mobile) and (limited past) surveyed model bathymetry may cause errors. Through modelling we are able to study the desired transects with continuous temporal information. For residual circulation this is important for capturing the 2-layer structure within the 706 channels, which is shown to vary between horizontally and vertically sheared depending on the dominant 707 process, tidal or baroclinic. Observations are often limited and have the potential to be discontinuous in space and/or time, inhibiting calculation of the residual (time-mean) conditions over a complete crosssection. These results can now be used to investigate the estuarine sediment dynamics (distribution and 710 net fluxes of different classes). Although the monthly residual circulation is dominated by the calm 
conditions, enhanced sediment transport during storm events may be important for net sediment flux. In

712 the Welsh Channel the residual flow suggests net sediment export may occur along the right side of the

713 channel (when facing offshore) and an import on the left. In the Hilbre Channel the residual flow suggests

714 net sediment export may occur in a surface layer and an import in a bottom layer. The height of the

715 sediment within the water column will be important within the Hilbre Channel as this will determine the

716 transport direction, which may vary during particle settling and re-suspension. The timing of each

717 process' contribution to the residual is investigated by Brown et al (submitted) and may be important

718 when considering transport pathways. Both Amoudry et al. (this issue) and Ramirez et al. (this issue)

719 have explored the sediment transport processes using this modelling system validating the time-varying

720 sediment concentrations in the Hilbre and Welsh Channels respectively, for this study period. The

721 combined channel dynamics over the long-term will determine how the estuary morphology will evolve,

722 while the net transport within these channels, particularly of different sediment classes, may differ.

723

724 Conclusion

725 The application of a barotropic-baroclinic-wave model has enabled a 30-day study of process 726 contributions to the time-averaged spatial patterns of the long-term residual in both elevation and Eulerian

727 circulation. The model has been applied to the Dee Estuary, a hypertidal estuary that has two main 728 channels, which have previously been found to display either tidal or baroclinic dominance (Bolaños et 729 al., 2013). Even during a (15-day) spring-neap period of stormy conditions, these two processes remain 730 dominant. This demonstrates that although storm impact is important at the event scale (Brown et al., 731 Submitted) it has lesser importance over longer (monthly) time scales for residual circulation within this 732 estuary.

734 This research looks at a longer (monthly) study period than previously investigated. The results from 735 these hypertidal channels with weak river flow show that the tide is not always the most important process 736 in generating residual circulation. The river-induced baroclinicity can be of primary or secondary 737 importance, even close to the estuary mouth under wave-current conditions. It is shown that adjacent estuary channels can display very different spatial (2D cross-sectional) residual circulation profiles that are predominantly driven by local processes, while similar patterns occur in the residual elevation driven 740 principally by hydrodynamic conditions external to the estuary and local (Liverpool Bay) region. 
742 This study compares a spring-neap cycle under both calm and stormy conditions, determined by a period

743 of observation. The Welsh Channel residual circulation is continually tidally dominant creating a 2-layer

744 horizontal structure. This is likely to create a net export of sediments and tracer properties on the right 745 side of the channel, with strongest flow near the surface. While a net import occurs along the left side.

746 Centrally over the deepest part of the channel a landward surface flow and seaward near bed flow occurs

747 as the two layers meet. In the Hilbre Channel the residual circulation is continually baroclinically 748 dominant creating a 2-layer vertical structure. This leads to a likely net export of sediments in the surface 749 layer and import in the thicker bottom layer. A metric is presented here to quantitatively compare process 750 contribution to the residual circulation. Although the estuary is sheltered from extreme wave activity the 751 3D wave-induced circulation weakly contributes to the time-averaged residual. However this contribution 752 should not be ignored (Bolaños et al., 2013). Over the long-term the influence of meteorology and waves 753 is weak. This means that the long-term time-averaged residual circulation is mainly controlled by the tide 754 and baroclinic processes, and is similar to that under calm current-dominant conditions. Since the 755 patterns in the profiles are similar for the calm and stormy period, the intermittent effect of storms (studied 756 by Brown et al., Submitted) does not change the structure of the $2 \mathrm{D}$ profiles only the magnitude of the 757 time-averaged residual circulation.

759 In both channels the residual elevation is primarily controlled by the external residual generated over a 760 longer fetch than that locally within Liverpool Bay, the local meteorological forcing has a secondary 761 influence and the waves are of tertiary importance under storm conditions (Brown et al., 2012a). Under 762 calm conditions, during this study, a set-down occurs. During stormy conditions more variable positive 763 and negative variations in residual elevation lead to a small time-averaged set-up. The 30-day time764 average is a set-down of a few centimetres, again showing dominance of the calm conditions in the 765 monthly residual, but this time for elevation. During stormy conditions any set-up which occurs may 766 increase the area inundated at high water and the duration of inundation of the intertidal, thus affecting 767 the exchange of particles (sediments / pollutants) or soluble traces between banks and channels at a time 768 when more turbulent conditions increase suspension rates and mixing. In the long-term the tide769 baroclinic conditions drive the net transport pathways, but storms may influence the transport rate. This 
772

773 Acknowledgments

774 We would like to thank the reviewers of this manuscript for helping focus the content of this manuscript.

775 This research has been carried out as part of Ocean 2025 and the projects FORMOST (NERC grant 776 NE/E015026/1), FIELD_AC (EU FP7 program grant 242284) and iCOASST (NERC grant NE/J005444/1).

777 Partial support was also been provided by the MERMAID EU (FP7-OCEAN.2011-1) project. Jane 778 Williams (NOC) is thanked for providing the operational surge model output and meteorological (wind and 779 780 781 782 783

study provides a good basis to now investigate the long-term sediment dynamics of an estuary system in response to the wave-circulation processes.

pressure) data, while Clare O'Neill (NOC, COBS) is thanked for providing the offshore temperature and salinity fields to the Irish Sea and supplementing the meteorological forcing with air temperature, humidity, and cloud cover to enable full atmospheric forcing.

\section{References}

Amoudry LO, Souza AJ, Brown, JM, Ramirez-Mendoza R. (this issue) Modelling-based assessment of suspended sediment dynamics in a hypertidal estuary. Ocean Dynamics, PECS special issue: Physics of Estuaries and Coastal Seas, New York, USA, 12-16th August 2012.

Bolaños R, Brown JM, Souza A (2011) Three dimensional circulation modeling in the Dee Estuary. Journal of Coastal Research SI (64), 1457-1461.

Bolaños R, Brown JM, Amoudry LO, Souza A (2013). Tidal, riverine and wind influences on the circulation of a macrotidal estuary. Journal of Physical Oceanography. 41(1), 29-50.

Bolaños R, Brown JM, Souza A (submitted) Wave-current interactions in a tidal dominated estuary. Submitted to Continental Shelf Research.

Bolaños R, Souza AJ (2010) Measuring hydrodynamics and sediment transport processes in the Dee Estuary. Earth System Science Data, 2, 157-165.

Brown JM, Souza AJ, Wolf $J(2010)$ An investigation of recent decadal-scale storm events in the eastern Irish Sea. Journal of Geophysical Research (Oceans). 115(C05018), 12pp.

Brown JM, Bolaños R, Howarth MJ, Souza A (2012a) Extracting sea level residual in tidally dominated estuarine environments. Ocean Dynamics, 62(7), 969-982. 
Brown JM, Bolaños R, Souza A (submitted) Process contribution to the time-varying residual circulation in tidally dominated estuarine environments. Submitted to Coasts and Estuaries.

Brown JM, Wolf J, Souza AJ (2012b) Future extreme events in Liverpool Bay: model projections from 1960 - 2100. Climatic Change, 11(2), 365-391.

Cáceres M, Valle-Levinson A, Atkinson L (2003) Observations of cross-channel structure of flow in an energetic tidal channel. Journal of Geophysical Research, 108(C4), 3114, 10pp.

Chen S-N, Stanford LP, Ralston DK (2009) Lateral circulation and sediment transport driven by axial winds in an idealized, partially mixed estuary. Journal of Geophysical Research, 114(C12006), $18 p p$.

Cheng P, de Swart HE, Arnoldo V-L (2013) Role of asymmetric tidal mixing in the subtidal dynamics of narrow estuaries, Journal of Geophysical Research - Oceans, 118(5), 2623-2639.

Deleersnijder, E,Beckers J-M (1992) On the use of the $\sigma$-coordinate system in regions of large bathymetric variations, Journal of Marine Systems, 3, 381-390.

Giddings SN, Monismith SG, Fong DA, Stacey MT (2013) Using depth-normalized coordinates to examine mass transport residual circulation in estuaries with large tidal amplitude relative to mean depth. Journal of Physical Oceanography. Doi:10.1175/JPO-D-12-0201.1 (in press)

Holt JT, James ID (2001) An s coordinate density evolving model of the northwest European continental shelf: 1, model description and density structure. Journal of Geophysical Research, 106 (C7):14,015-14,034.

Holt J, Proctor R (2008) The seasonal circulation and volume transport on the northwest European continental shelf: A fine-resolution model study, Journal of Geophysical Research, 113, C06021, 20pp.

Horsburgh KJ, Wilson C (2007) Tide-surge interaction and its role in the distribution of surge residuals in the North Sea. Journal of Geophysical Research 112(C08003). doi:10.1029/2006JC004033

Jones JE, Davies AM (1998) Storm surge computations for the Irish Sea using a three-dimensional numerical model including wave-current interaction. Continental Shelf Research 18(2):201-251.

Komen GJ, Cavaleri L, Donelan M, Hasselmann K, Hasselmann S, Janssen PAEM (1994) Dynamics and modelling of ocean waves. Cambridge University Press, Cambridge, 532pp. 
Kasai A, Hill E, Fujiwara T, Simpson JH (2000) Effect of the Earth's rotation on the circulation in regions of freshwater influence. Journal of Geophysical Research 105(C7): 16,961-16,969.

Li C, O'Donnell J (2005) The effect of channel length on the residual circulation in tidally dominated channels. Journal of Physical Oceanography 35(10), 1826-1840.

Li C, Weeks E, Blanchard BW (2010) Storm surge induced flux through multiple tidal passes of Lake Pontchartrain estuary during Hurricanes Gustav and Ike. Estuarine, Coastal and Shelf Science, 87(4):517-525.

Li C, Weeks E, Rego JL (2009) In situ measurements of saltwater flux through tidal passes of Lake Pontchartrain estuary by Hurricanes Gustav and Ike in September 2008, Geophysical Research Letters, 36(L19609): 5pp, doi:10.1029/2009GL039802.

Mellor G (2005) Some consequences of the three-dimensional current and surface wave equations. Journal of Physical Oceanography, 35(11), 2291-2298.

Monbaliu J, Padilla-Hernández R, Hargreaves JC, Carretero-Albiach JC, Luo W, Sclavo M, Günther H (2000) The spectral wave model WAM adapted for applications with high spatial resolution. Coastal Engineering, 41(1-3), 41-62.

Polton JT, Palmer MR, Howarth MJ (2011) Physical and dynamical oceanography of Liverpool Bay, Ocean Dynamics, 61(9), 1421-1439.

Proudman, J. (1957) Oscillations of tide and surge in an estuary of finite length, Journal of Fluid Mechanics, 2, 371-382.

Ramirez-Mendoza R., Souza AJ, and Amoudry LO (this issue) Modelling flocculation in a hypertidal estuary. Ocean Dynamics, PECS special issue: Physics of Estuaries and Coastal Seas, New York, USA, 12-16th August 2012.

Rossiter JR (1961) Interactions between tide and surge in the Themes. Geophysical Journal of the Royal Astronomical Society, 6(1), 29-53.

Scully ME, Friedrichs C, Brubaker J (2005) Control of estuarine stratification and mixing by wind-induced straining of the estuarine density field. Estuaries and Coasts, 28(3), 321-326.

Simpson JH, Brown J, Matthews J, Allen G (1990) Tidal straining, density currents, and stirring in the control of estuarine stratification. Estuaries, 13(2), 125-132.

Souza AJ (2013) On the use of the Stokes number to explain frictional tidal dynamics and water column structure in shelf seas. Ocean Science, 9(2), 391-398 
857 Umlauf L, Burchard H (2005). Second-order turbulence closure models for geophysical boundary layers. A review of recent work. Continental Shelf Research 25(7-8), 795-827.

859 Valle-Levinson A, Reyes C, Sanay R (2003) Effects of bathymetry, friction and rotation on estuary-ocean 860 exchange, Journal of Physical Oceanography, 33(11), 2375-2393.

861 Verspecht F, Rippeth TP, Howarth MJ, Souza AJ, Simpson JH, Burchard H (2009) Processes impacting 862 on stratification in a region of freshwater influence: application to Liverpool Bay. Journal of 863 Geophysical Research (Oceans), 114 (C11022). 12pp.

864 Willmott CJ, Ackleson SG, Davis RE, Feddema JJ, Klink KM, Legates DR, O’Donnell J, Rowe CM (1985) 865 Statistics for the evaluation and comparison of models. Journal of Geophysical Research 866 90(C5), 8995-9005.

867 Winant CD (2008) Three-dimensional residual tidal circulation in an elongated, rotating basin. Journal of 868 Physical Oceanography, 38(6), 1278-1295. 